\title{
Arranjo produtivo do artesanato na Região Metropolitana de Belém: uma caracterização empírica
}

Marcelo Bentes Diniz - Doutor em Desenvolvimento Econômico e Regional pelo CAENUFC.

Márcia Jucá Teixeira Diniz - Doutora em Desenvolvimento Sustentável pelo NAEAUFPA.

\section{Resumo}

Este artigo apresenta o artesanato na Região Metropolitana de Belém, abordando as suas características enquanto arranjo produtivo. Assim, com base em dados primários obtidos em uma pesquisa de campo realizada em 2005 pelos autores e em dados secundários de uma pesquisa realizada pelo SEBRAE em 2002, são destacados aspectos empíricos do funcionamento desse arranjo, que se assenta em cinco elementos principais: a empresa e os empreendedores, a dinâmica de aprendizado, conhecimento e inovação, cooperação e a governança. Como resultados obtidos da aplicação de um formulário desenvolvido pela Redesist (Instituto de Economia da Universidade Federal do Rio de Janeiro), destacam-se as relações de trabalho de cunho familiar, o baixo profissionalismo e o baixo grau baixo de cooperação, ainda que exista um caráter inovador especialmente em produtos.

\section{Palavras-chave}

Artesanato; Região Metropolitana de Belém.

\section{Abstract}

This article presents the handicraft industry in the Metropolitan Region of Belém, treating it as a productive arrangement. Primary data obtained from field work carried out in 2005 by the authors, was combined with secondary data from research carried out by SEBRAE in 2002. The most significant empirical aspects regarding the functioning of this arrangement are constituted by five main elements: the company and entrepreneurs, dynamics of innovation, learning, knowledge and cooperation and, finally, the most significant aspects of its management. The questionnaire developed by Redesist (IE-UFRJ) regarded the activities connected with handicrafts and was given to directly to the "producers", in accordance with a representative sample. Among the results obtained, the most significant were the relations of family work, a lack of professionalism, a low degree of cooperation, despite innovations with respect to new products.

\section{Keywords}

Handcraft industry; Metropolitan Region of Belém. 


\section{INTRODUÇÃO}

Como bem ressaltado pelo Plano Amazônia Sustentável (PAS), a Amazônia brasileira caracteriza-se por uma grande diversidade étnica, social e cultural. Há diferenciações significativas tanto na própria população nativa quanto na população que migrou para a região e entre seus descendentes. Além disso, os grupamentos urbanos existentes nas largas fronteiras da Amazônia Ocidental sofrem influência dos povos que habitam os sete países de fronteira e, no caso do Pará, em especial da Guiana, da Guiana Francesa e do Suriname.

Assim, o traço característico principal da cultura do povo amazônico é a diversidade, que tem um duplo caráter: de uma parte, há uma diversidade que pode ser considerada endógena, resultante da evolução dos vários povos autóctones, aquilo que Mendes (2001) classificou como "amazonidades", isto é, a singularidade da realidade (local) da Amazônia - características culturais geradas in loco e sponte sua e não contraídas por qualquer tipo de contágio ou exposição a outras influências; de outra parte, há uma diversidade exógena, fruto dos vários ciclos de migração que a região recebeu ao longo de sua história de colonização.

A riqueza cultural expressa-se em muitas e diferentes manifestações, algumas delas de caráter inovador, seja porque são singulares, não aparecendo em nenhuma outra região do país, seja porque assumem na região aspectos peculiares, em consonância com as especificidades da tradição e dos hábitos locais. O artesanato é um típico exemplo nessa direção.

Além disso, o artesanato, pelas suas características, por ser um conjunto de unidades produtivas, pode ser interpretado como um arranjo produtivo local (APL), uma vez que congrega em uma mesma territorialidade agentes econômicos que mantêm vínculos consistentes de articulação, interação, cooperação e aprendizagem (CASSIOLATO; LASTRES, 2003a; LASTRES; CASSIOLATO; ARROIO, 2005). De fato, embora a expressão "arranjo produtivo local" tenha assumido diferentes conotações, adotou-se a definição proposta pela Rede de Pesquisa em Sistemas e Arranjos Produtivos e Inovativos Locais (Redesist) ${ }^{1}$, que acentua os seguintes pontos: i) aglomeração produtiva com uma certa especialidade - as unidades produtivas de uma dada atividade produtiva, independentemente de seu grau de formalidade, exploram um ou mais produtos com características muito próximas; ii) espacialidade local - em uma espacialidade definida, que pode ser um município, uma região metropolitana ou um Estado, essas unidades produtivas de alguma forma interagem; iii) cooperação - criamse vínculos sistêmicos entre as unidades daquele aglomerado naquele espaço, havendo alguma forma de coordenação ou não; iv) aprendizado

${ }^{1}$ Ligada ao Instituto de Economia da Universidade Federal do Rio de Janeiro. 
formal ou não - o que explicaria a dinâmica do processo "bem-sucedido" de inovações, entendido como a base do desenvolvimento e da competitividade adquirida por aquela aglomeração, que lhe asseguram um papel de destaque na economia daquela espacialidade local.

Os dados obtidos neste artigo baseiam-se em duas fontes: pesquisa de campo realizada em 2005 e pesquisa realizada pelo Serviço Brasileiro de Apoio às Micro e Pequenas Empresas (SEBRAE) em 2002. Para as atividades ligadas ao artesanato, foi aplicado diretamente ao "produtor" o formulário desenvolvido pela Redesist, a partir da definição de uma amostra representativa.

Com objetivo de destacar os aspectos empíricos do funcionamento do arranjo produtivo do artesanato, este artigo compreende quatro seções, além desta introdução e das considerações finais. A primeira aborda os aspectos gerais e específicos do arranjo produtivo do artesanato na Região Metropolitana de Belém (RMB). A segunda trata de alguns aspectos relacionados à empresa e ao empreendedor. A terceira apresenta as características da dinâmica de inovação. A quarta examina os elementos ligados ao treinamento, ao aprendizado e à cooperação.

\section{ASPECTOS GERAIS DO ARRANJO PRODUTIVO DO ARTESANATO NA REGIÃO METROPOLITANA DE BELÉM}

Neste artigo, artesanato diz respeito ao conjunto das atividades cuja produção depende diretamente, em pelo menos uma etapa do processo produtivo, da figura do artesão, que a realiza de forma manual, com o auxílio ou não de instrumentos de produção. Isso quer dizer que, ainda que seja possível a produção em série de uma dada peça, seu modo de fazer sempre envolve o artesão, nem que seja no acabamento e na finalização da peça.

De uma maneira geral, a atividade artesanal desenvolvida na Região Metropolitana de Belém apresenta as mesmas características do artesanato em geral: pouca e rudimentar utilização de equipamentos e máquinas; divisão de tarefas, quando existe, baseada no gênero, os homens assumindo as tarefas manuais mais pesadas, enquanto as mulheres assumem funções ligadas ao acabamento e à decoração.

Não obstante essas características, o conjunto da atividade, por suas relações e interações sistêmicas, coaduna-se com a definição adotada de arranjo produtivo, embora, por certas especificidades, mais se aproxime da tipologia adotada por Santos et al. (2002), enquanto APL informal:

a) estrutura organizacional de caráter familiar, o que fragiliza a capacidade administrativa e de gestão e acaba repercutindo diretamente em outras duas características: a baixa produtividade e a baixa qualificação da mão-de-obra;

b) formas razoavelmente consolidadas de associativismo e cooperação;

c) elevada informalidade; 
d) segmentação que ocorre a partir da matéria-prima principal utilizada;

e) formas de aprendizado e de reprodução do conhecimento cujo fundamento é a estrutura familiar, baseadas no processo learning by doing/learning by using, e não no conhecimento sistematizado;

f) grande potencial inovativo nas duas atividades, embora concretamente a capacidade inovativa para gerar progresso tecnológico possa ser considerada débil.

A informalidade imprime ao arranjo produtivo um duplo caráter. De um lado, o detentor do negócio informal exerce simultaneamente as funções de empregado e de patrão, gestor e produtor (CACCIAMALI, 1983, 2000). Segundo Kon (2004), trata-se de um conjunto de formas de organização da produção e de distribuição que se estabelecem no interior da produção capitalista, muito embora subordinadas e integradas a esta. De outro, o trabalho informal tem a natureza de um auto-emprego: o objetivo do empreendedor não é exatamente o lucro capitalista, mas a criação de condições para assegurar a sua manutenção e a de sua família (PAMPLONA, 1999).

Há de se destacar, ainda, duas características do artesanato paraense que podem ser ditas diferenciadas:

a) retratam o modo peculiar de "fazer", a partir do "saber" típico da cultura nativa, com peças que reproduzem, em sua maior parte, o cotidiano da relação homem-natureza do caboclo amazônida;

b) caracterizam-se pela diversidade, manifesta nos materiais utilizados, e pela variedade de composição e das técnicas utilizadas (exemplos: argila, madeiras, miriti, balatas, conchas, minerais, couros, sucatas, cipós, raízes, frutos e outros, utilizados para peças de cerâmica, cestarias, instrumentos musicais, bijuterias e brinquedos).

As peças de cerâmicas têm como referência duas formas principais: a cerâmica tapajônica e a cerâmica marajoara. São artefatos comuns: vasos, urnas, estatuetas, animais, tangas e peças utilitárias, como pratos, panelas, fruteiras e galheteiros.

A balata é o látex extraído da seringueira, com o qual são confeccionados pequenos animais, como boto, arara, macaco, peixeboi, cobra, peixes, ou representados caboclos em suas situações cotidianas: pescando, montando a cavalo, ordenhando vaca etc.

A cestaria compreende não só cestas propriamente ditas, mas também jogos americanos, tapetes, chapéus, abanos, fruteiras, portabolos, revisteiros, bolsas etc.

A originalidade da arte do miriti destaca-se realmente na arte paraense. Sua matéria-prima é a tala das palmeiras do miritizeiro. Duas características do miriti tornam atrativos os brinquedos e outros utensílios domésticos: a flexibilidade e a leveza. Dentre os mais diversos utensílios fabricados com miriti, destaca-se a produção de barcos, canoas, aviões, pássaros amazônicos, "come-come", caixas de brinquedo, utensílios de decoração. 
O artesanato indígena compreende inúmeras peças confeccionadas com cipós, fibras, folhas, frutos, ossos, penas, madeira, entre outros materiais. Há remos, cocares, testeiras e braçadeiras, bolsas, redes, saias, cuias. As cuias destacam-se não somente como peças decorativas, mas também como utensílio: nelas, bebe-se o tacacá.

Os instrumentos musicais também de origem indígena, na sua maioria, abarcam diferentes tipos e finalidades. São, em geral, instrumentos de percussão, como os ganzás e as maracás de coco, mas também são produzidos instrumentos de sopro.

Os utensílios de madeira também são muito explorados pelo artesanato local. Destacam-se os brinquedos de madeira - principalmente barcos, bomboneiras, fruteiras, vasos, porta-jóias, porta-cerveja, copos e taças, pilões, farinheiras, animais decorativos, talhas entre outros.

Os minerais são importantes na confecção de jóias, aproveitandose a variedade de minerais metálicos e não-metálicos existentes na região. Os tipos de minerais mais utilizados são as gemas.

As bijuterias utilizam, em geral, sementes combinadas com outros materiais. As peças mais fabricadas são: colares, pulseiras, e brincos. Há produtos feitos com sucata da floresta - cascas de frutos, cipós, por exemplo. Um outro produto também muito utilizado para bijuterias é a jarina.

Uma agregação de valor importante, que atinge diferentes segmentos, tem sido a combinação de vários tipos de artesanato. No artesanato de jóias, por exemplo, são utilizadas gemas, metais diversos, preciosos ou semipreciosos, juntamente com diversos tipos de fibras, frutos e cipós.

\section{O EMPREENDEDOR E A EMPRESA}

Foram pesquisadas 45 microempresas comportando 287 empregados, o que resulta em uma média de aproximadamente 6 trabalhadores por empresa.

Na pesquisa de campo, observou-se que mais de 95\% das unidades pesquisadas são microempresas, tendo menos de dez empregados; somente uma foi classificada como pequena e uma, como média. Cerca de 50\% das microempresas foram fundadas antes de 1980, todas formadas por capital nacional; cerca de 90\% dessas empresas têm um ou dois sócios.

\section{$2.1 \mathrm{O}$ sócio fundador}

O perfil do sócio fundador é destacado na Tabela 1, na qual são apresentadas características como idade, sexo, influência paterna, escolaridade e atividade exercida antes que o artesanato se tornasse a atividade principal. 
Tabela 1: Perfil do sócio fundador.

\begin{tabular}{|c|c|c|c|}
\hline Especificação & Micro & Pequena & Média \\
\hline \multicolumn{4}{|l|}{ 1. Idade } \\
\hline 1.1. Até 20 anos & $40,00 \%$ & $0,00 \%$ & $0,00 \%$ \\
\hline 1.2. Entre 21 e 30 anos & $31,10 \%$ & $0,00 \%$ & $100,00 \%$ \\
\hline 1.3. Entre 31 e 40 anos & $15,60 \%$ & $100,00 \%$ & $0,00 \%$ \\
\hline 1.4. Entre 41 e 50 anos & $4,40 \%$ & $0,00 \%$ & $0,00 \%$ \\
\hline 1.5. Acima de 50 anos & $4,40 \%$ & $0,00 \%$ & $0,00 \%$ \\
\hline Total & $95,60 \%$ & $100,00 \%$ & $100,00 \%$ \\
\hline \multicolumn{4}{|l|}{ 2. Sexo (\%) } \\
\hline 2.1. Masculino & $53,30 \%$ & $0,00 \%$ & $100,00 \%$ \\
\hline 2.2. Feminino & $44,40 \%$ & $100,00 \%$ & $0,00 \%$ \\
\hline Total & $97,80 \%$ & $100,00 \%$ & $100,00 \%$ \\
\hline \multicolumn{4}{|l|}{ 3. Pais empresários (\%) } \\
\hline 3.1. Sim & $40,00 \%$ & $0,00 \%$ & $100,00 \%$ \\
\hline 3.2. Não & $48,90 \%$ & $0,00 \%$ & $0,00 \%$ \\
\hline Total & $88,90 \%$ & $0,00 \%$ & $100,00 \%$ \\
\hline \multicolumn{4}{|l|}{ 4. Escolaridade (\%) } \\
\hline 4.1. Analfabeto & $2,20 \%$ & $0,00 \%$ & $0,00 \%$ \\
\hline 4.2. Ensino fundamental incompleto & $28,90 \%$ & $0,00 \%$ & $0,00 \%$ \\
\hline 4.3. Ensino fundamental completo & $31,10 \%$ & $0,00 \%$ & $0,00 \%$ \\
\hline 4.4. Ensino médio incompleto & $13,30 \%$ & $0,00 \%$ & $0,00 \%$ \\
\hline 4.5. Ensino médio completo & $17,80 \%$ & $0,00 \%$ & $0,00 \%$ \\
\hline 4.6. Superior incompleto & $2,20 \%$ & $0,00 \%$ & $100,00 \%$ \\
\hline 4.7. Superior completo & $4,40 \%$ & $0,00 \%$ & $0,00 \%$ \\
\hline 4.8. Pós-graduação & $0,00 \%$ & $100,00 \%$ & $0,00 \%$ \\
\hline Total & $100,00 \%$ & $100,00 \%$ & $100,00 \%$ \\
\hline \multicolumn{4}{|l|}{ 5. Atividade antes de criar a empresa (\%) } \\
\hline & $4,40 \%$ & $0,00 \%$ & $0,00 \%$ \\
\hline 5.2. Estudante de escola técnica & $2,20 \%$ & $0,00 \%$ & $0,00 \%$ \\
\hline 5.3. Empregado de micro ou pequena empresa local & $6,70 \%$ & $0,00 \%$ & $0,00 \%$ \\
\hline $\begin{array}{l}\text { 5.3. Empregado de micro ou pequena empresa local } \\
\text { 5.4. Empregado de média ou grande empresa local }\end{array}$ & $2,20 \%$ & $0,00 \%$ & $0,00 \%$ \\
\hline 5.5. Empregado de empresa de fora do arranjo & $0,00 \%$ & $0,00 \%$ & $0,00 \%$ \\
\hline 5.6. Funcionário de instituição pública & $6,70 \%$ & $0,00 \%$ & $0,00 \%$ \\
\hline 5.7. Empresário & $13,30 \%$ & $0,00 \%$ & $0,00 \%$ \\
\hline \multirow[t]{2}{*}{ 5.8. Outra } & $64,40 \%$ & $100,00 \%$ & $100,00 \%$ \\
\hline & $100,00 \%$ & $100,00 \%$ & $100,00 \%$ \\
\hline
\end{tabular}

Fonte: pesquisa de campo.

Assim, destacam-se os seguintes aspectos: a) há uma relativa igualdade por gênero na execução das atividades, pelo menos quanto ao sócio da empresa, que, em geral, é por assim dizer o "mestre-artesão"; b) a escolaridade é baixa, prevalecendo o ensino fundamental incompleto $(31,7 \%)$ ou completo $(29,3 \%) ;$ c) a idade prevalecente é até 20 anos (39\%) e entre 21 e 40 anos (34,1\%); d) cerca da metade tem pais empresários.

Um outro ponto que merece ser destacado é a baixa idade dos sócios fundadores. A explicação para isso está, em parte, no fato de a empresa ter adquirido recentemente uma natureza formal, muito embora já existisse, em alguns casos por mais de uma década, como mostrou a 
Tabela 1. Isso revela, na verdade, uma nova geração de artesãos que, com maior grau de instrução (6,6\% com grau superior completo ou incompleto) do que seus pais, perceberam que a formalidade abre novas oportunidades de negócios para as unidades produtivas.

\subsection{Características gerais do processo produtivo}

Tanto o local como as relações de trabalho têm na família seu núcleo central. De fato, como evidenciado pela Tabela 2 , em pouco mais de $77 \%$ dos casos, a execução da atividade é realizada na própria residência do artesão, prevalecendo relações de trabalho com mão-deobra tipicamente familiar (cf. Tabela 3).

Tabela 2: Local de trabalho (2002).

\begin{tabular}{l|r|r}
\hline \multicolumn{1}{c|}{ Local de trabalho } & Absoluto & \multicolumn{2}{c}{ Relativo } \\
\hline Residência & 463 & 77,3 \\
Associação & 6 & 1 \\
Oficina alugada & 30 & 5 \\
Outros & 100 & 16,7 \\
\multicolumn{1}{c}{ Total } & 599 & 100 \\
\hline
\end{tabular}

Fonte: SEBRAE; ACERTAR, 2002

Tabela 3: Como a atividade artesanal é desenvolvida (2002).

\begin{tabular}{lrrr}
\hline \multicolumn{1}{c}{ Origem } & Absoluto & Relativo \\
\hline Individualmente & 260 & 41,5 \\
Com familiares & 275 & 43,9 \\
Com outros artesãos & 63 & 10,1 \\
Com aprendizes & 28 & 4,5 \\
\multicolumn{1}{c}{ Total } & 599 & 100 \\
\hline
\end{tabular}

Fonte: SEBRAE; ACERTAR, 2002.

Como prevalece uma estrutura familiar, a relação de trabalho dominante envolve familiares sem contrato formal, ainda que esse processo venha cedendo espaço para relações formais de trabalho. É importante dizer que, nas formas de informalidade, incluem-se os serviços de caráter temporário.

Tabela 4: Relação de trabalho.

\begin{tabular}{l|c|c|c|c|c|c}
\hline \multirow{2}{*}{ Tipos } & \multicolumn{2}{c|}{ Micro } & \multicolumn{2}{c|}{ Pequena } & \multicolumn{2}{c}{ Média } \\
\cline { 2 - 7 } & $\mathrm{N}^{\circ}$ pessoas & $\%$ & $\mathrm{~N}^{\circ}$ pessoas & $\%$ & $\mathrm{~N}^{\circ}$ pessoas & $\%$ \\
\hline Sócio proprietário & 63 & $18,50 \%$ & 1 & $5,90 \%$ & 1 & $1,60 \%$ \\
Contratos formais & 62,5 & $18,40 \%$ & 8 & $47,10 \%$ & 0 & $0,00 \%$ \\
Estagiário & 3,5 & $1,00 \%$ & 2 & $11,80 \%$ & 0 & $0,00 \%$ \\
Serviço temporário & 41 & $12,10 \%$ & 1 & $5,90 \%$ & 60 & $98,40 \%$ \\
Terceirizados & 90 & $26,50 \%$ & 5 & $29,40 \%$ & 0 & $0,00 \%$ \\
Familiares sem & & & & & & \\
contrato formal & 79,8 & $23,50 \%$ & 0 & $0,00 \%$ & 0 & $0,00 \%$ \\
$\quad$ Total & 340 & $100 \%$ & 17 & $100 \%$ & 61 & $100 \%$ \\
\hline
\end{tabular}

Fonte: pesquisa de campo. 
A escolaridade do pessoal ocupado apresenta dois aspectos interessantes: não foram constatados trabalhadores analfabetos entre os ocupados na atividade; o grau de escolaridade aumenta conforme aumenta o tamanho da empresa.

Tabela 5: Escolaridade do pessoal ocupado.

\begin{tabular}{lcccc}
\hline \multicolumn{1}{c}{ Grau de Ensino } & Micro & Pequena & Média \\
\hline 1. Analfabeto & 0 & 0 & 0 \\
& $0,00 \%$ & $0,00 \%$ & $0,00 \%$ \\
\hline 2. Ensino fundamental incompleto & 75 & 0 & 60 \\
\hline 3. Ensino fundamental completo & $29,20 \%$ & $0,00 \%$ & $98,40 \%$ \\
\hline 4. Ensino médio incompleto & 33,6 & 0 & 0 \\
& $13,10 \%$ & $0,00 \%$ & $0,00 \%$ \\
\hline 5. Ensino médio completo & 51 & 0 & 0 \\
& $19,80 \%$ & $0,00 \%$ & $0,00 \%$ \\
\hline 6. Superior incompleto & 83,4 & 8 & 0 \\
& $32,50 \%$ & $72,70 \%$ & $0,00 \%$ \\
\hline 7. Superior completo & 4 & 0 & 0 \\
& $1,60 \%$ & $0,00 \%$ & $0,00 \%$ \\
\hline 8. Pós-graduação & 6 & 2 & 1 \\
& $2,30 \%$ & $18,20 \%$ & $1,60 \%$ \\
\hline \multicolumn{1}{c}{ Total } & 4 & 1 & 0 \\
\hline
\end{tabular}

Fonte: pesquisa de campo.

Em sua análise socioeconômica dos arranjos produtivos, Noronha e Turchi (2005) destacam a importância da base familiar dos empreendimentos. Segundo esses autores, a cooperação, tão ressaltada nos APL, envolve várias relações: i) autoridade, ii) mecanismos de controle explícitos típicos de relações familiares, iii) reconhecimento de interesses mútuos, iv) sedimentação da confiança, enquanto antecipação do comportamento do delegatário. Essas características efetivamente marcam o artesanato paraense em seus variados segmentos. O vínculo familiar é decisivo na relação de confiança que se estabelece para a transmissão do conhecimento, que permite dar continuidade à "tradição de família". Ao mesmo tempo, nas relações de trabalho, a autoridade e as formas de controle do trabalho são impostas muito mais pela própria hierarquia familiar do que por alguma imposição legal ou jurídica. Além disso, a ocupação de membros da família na atividade artesanal representa uma expansão da força de trabalho e da capacidade produtiva da empresa; mais do que uma forma de aumentar o lucro a ser recebido, é uma forma de aumentar a renda familiar. Essa característica, entretanto, tem estreita vinculação com o grau de formalização da empresa (artesanato) e varia de acordo com o tipo específico de artesanato. Assim, enquanto os artesãos do segmento de produção de ervas, balata, cuia, cestaria e cerâmica 
assumem essa característica explicitamente, o mesmo não se observa no segmento de produção de jóias artesanais.

A matéria-prima utilizada nos trabalhos artesanais pode ser natural ou industrial, mas, no artesanato paraense, prevalece a matéria-prima de origem natural (Tabela 6), o que reforça o que foi dito anteriormente sobre sua peculiaridade.

Tabela 6: Origem da matéria-prima (2002).

\begin{tabular}{l|rr}
\hline \multicolumn{1}{c|}{ Origem } & Absoluto & \multicolumn{2}{c}{ Relativo } \\
\hline Natural & 412 & 68,8 \\
Industrial & 101 & 16,9 \\
Natural/industrial & 86 & 14,4 \\
\multicolumn{1}{c}{ Total } & 599 & 100 \\
\hline
\end{tabular}

Fonte: SEBRAE; ACERTAR, 2002.

Grande parte dessa matéria-prima é originada da chamada região das ilhas de Belém e de municípios vizinhos, como Igarapé-Miri e Abaetetuba.

Observa-se, na Tabela 7, que as vendas são feitas diretamente ao consumidor, na maioria das vezes na própria casa ou na oficina do produtor, ou em mercados ou feiras. De fato, apenas cerca de 10\% dos produtores possuem loja própria, 12,4\% vendem direto a lojistas e 11\%, por meio de intermediários.

Tabela 7: Sistema de vendas (2002).

\begin{tabular}{l|r|r}
\hline \multicolumn{1}{c}{ Origem } & Absoluto & Relativo \\
\hline Diretamente ao consumidor & 338 & 34,3 \\
Em mercados, praças & 228 & 23,1 \\
Diretamente a lojistas & 122 & 12,4 \\
Por meio de intermediários & 111 & 11,3 \\
Em loja própria & 93 & 9,4 \\
Outros & 40 & 4,1 \\
Por meio de associações & 43 & 4,4 \\
Por meio de cooperativas & 11 & 1,1 \\
\multicolumn{1}{c}{ Total } & 986 & 100 \\
\hline
\end{tabular}

Fonte: SEBRAE; ACERTAR, 2002.

É na associação, que permite a comercialização da produção em feiras e mercados, em espaços públicos em geral, sob a coordenação do Estado, que se manifesta a cooperação entre os artesãos - como será ressaltado em seção posterior.

Quanto às feiras, destaca-se a "Feira do Artesanato" realizada na praça da República, em Belém. Em 150 barracas padronizadas, são comercializados diversos tipos de artesanato. A feira congrega produtores de cinco associações de artesãos - Associação de Microprodutores e Artesãos do Guamá (AMPAG), Associação das Mulheres Artesãs de 
Icoaraci (AMAI), Cooperativa dos Artesãos de Icoaraci (COART), Associação dos Artífices e Produtores de Icoaraci (AAPI) e Cooperativa dos Microprodutores e Artesãos da Área Metropolitana de Belém (COMIP) -, além de três entidades filantrópicas: República do Pequeno Vendedor, Grupo de Aposentados e Pensionistas da Prefeitura Municipal de Belém (PMB) e Fundação Papa João XXIII.

Outro espaço importante para a comercialização dos produtos artesanais é o "Espaço São José Liberto", onde mais de 300 artesãos expõem, em regime de consignação, em caráter permanente. Além desses, outros pontos de exposição pública são a Estação das Docas, o Mangal das Garças e o Mercado de São Braz.

Por sua vez, segundo o Sindilojas, 25 é o número de estabelecimentos que comercializam artesanato em Belém.

A renda bruta, em 85\% dos casos, girava em torno de 1 a 5 salários mínimos (SM), o que corresponde à remuneração média da população da Região Metropolitana de Belém trabalhando no setor informal por conta própria ou na condição de empregador (IBGE, 2005).

Tabela 8: Renda bruta mensal (2002).

\begin{tabular}{lrr}
\hline \multicolumn{1}{c|}{ Renda Bruta em Salários Mínimos } & Absoluto & Relativo \\
\hline Até 1 SM & 160 & 26,7 \\
Mais de 1 e até 5 SM & 350 & 58,4 \\
Mais de 5 e até 10 SM & 66 & 11 \\
Não sabe $\quad$ Total & 23 & 3,8 \\
\multicolumn{1}{c}{ Tal } & 599 & 100 \\
\hline
\end{tabular}

Fonte: SEBRAE; ACERTAR, 2002.

Um aspecto especialmente importante do sistema de produção, como pode ser visualizado na Tabela 9, está relacionado com as dificuldades encontradas pelas unidades produtivas para realizar a produção. Observa-se que a maioria das dificuldades permanece no mesmo nível (medido pelo índice), tanto no primeiro ano, como quando comparado com o ano de 2005. Todavia, a dificuldade de produzir com qualidade diminuiu bastante graças ao próprio processo de aprendizagem, que tem permitido melhoras nessa direção. Mantém-se também a dificuldade de contratar empregados qualificados.

Essas dificuldades são confirmadas pelos resultados da pesquisa realizada pelo Instituto Brasileiro de Geografia e Estatística (IBGE) em 2003 para o setor informal. Nessa pesquisa, constatou-se que a falta de capital próprio e a falta de acesso ao crédito são duas das maiores dificuldades encontradas por quem trabalha na informalidade. 
Tabela 9: Dificuldades enfrentadas pela empresa.

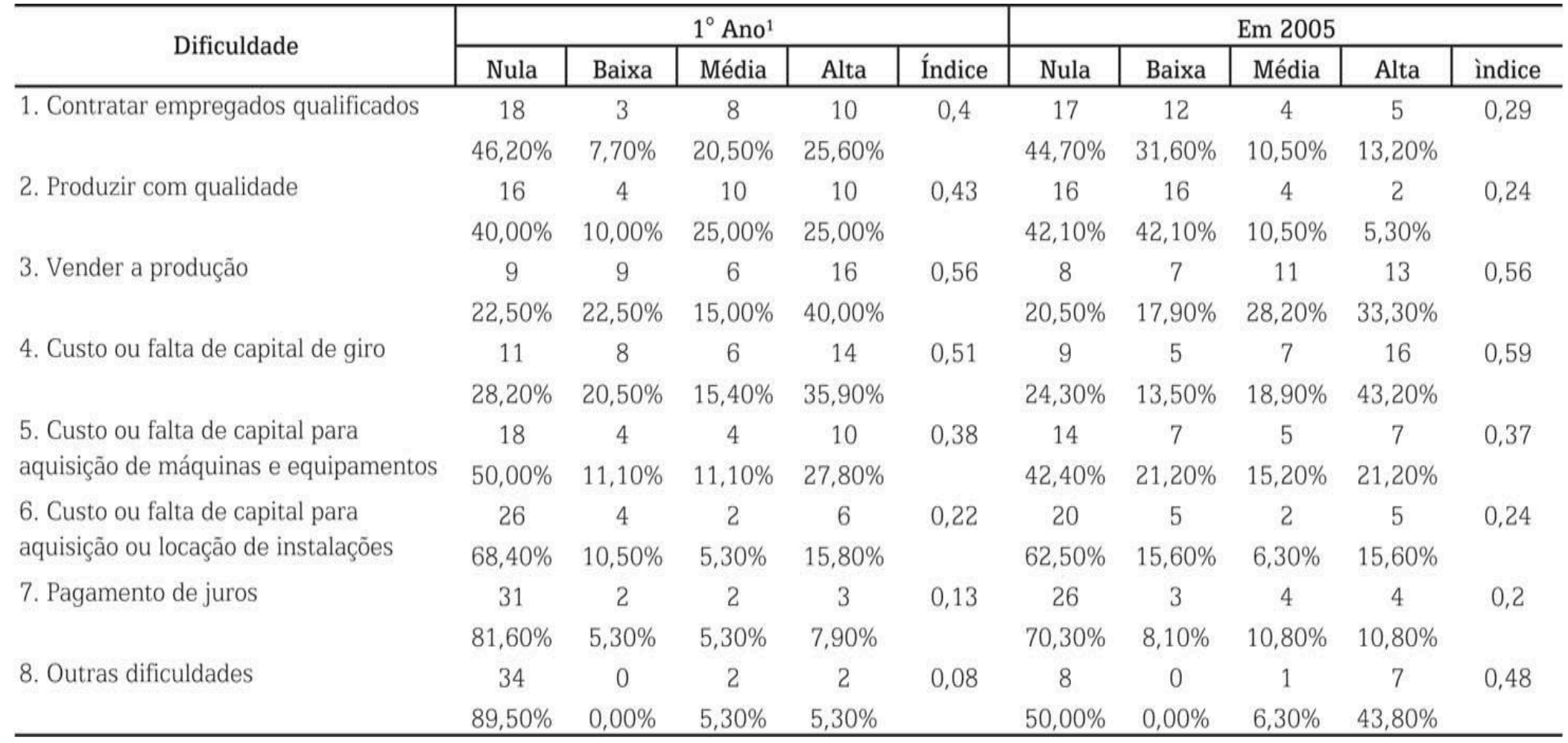

Fonte: pesquisa de campo.

*Índice $=\left(0^{*} \mathrm{~N}^{\circ}\right.$ nulas $+0,3 * \mathrm{~N}^{\circ}$ baixas $+0,6^{*} \mathrm{~N}^{\circ}$ médias $+\mathrm{N}^{\circ}$ altas $) /\left(\mathrm{N}^{\circ}\right.$ empresas no segmento).

1 O "1‥ Ano" é o primeiro ano de operação das empresas pesquisadas. Sendo assim, são anos variados. 
Contrastam com os resultados apresentados na Tabela 9 aqueles relativos aos fatores competitivos apontados pelas unidades produtivas como determinantes para manter sua capacidade competitiva na principal linha de produção da empresa. Por ordem de importância, são apontados os seguintes: desenho e estilo dos produtos, qualidade dos produtos, qualidade da matéria-prima, qualidade da mão-de-obra e capacidade de atendimento.

Para os produtores artesanais, é evidente que o diferencial de seus produtos está na sua originalidade, no uso de utensílios e de matériaprima natural que imprimem a marca "Amazônia" em seus produtos. Eles sabem, porém, que isso não garante mercado, dada a grande concorrência que marca os diversos segmentos, principalmente quando há a intenção de exportar a produção, em âmbito nacional ou no exterior. Assim sendo, a qualidade da matéria-prima, a qualidade do produto, bem como a capacidade de atendimento dos pedidos, em geral, em maior escala, quando a venda é feita a atacadistas intermediários, passam a ser consideradas efetivamente como fatores determinantes da manutenção dos mercados alcançados. Os produtores artesanais crêem que a diferenciação do produto só representa realmente uma vantagem competitiva quando aliada a outros elementos que agregam valor ao produto e à empresa.

A Tabela 10 mostra os fatores determinantes da competitividade apontados pelas unidades produtivas. Destacam-se o estilo e o desenho dos produtos, a qualidade da matéria-prima e da mão-de-obra e, por extensão, a qualidade do produto.

As características do processo produtivo, especialmente quanto às relações de trabalho, são semelhantes àquelas que definem a informalidade no setor terciário (OIT, 1972): i) facilidade de entrada; ii) propriedade individual ou familiar do empreendimento; iii) operação em pequena escala; iv) utilização de materiais nacionais - no caso específico, "regionais"; v) processos produtivos intensivos em trabalho por meio de tecnologia adaptada; vi) atuação em mercados não regulamentados e altamente competitivos; vii) qualificação dos trabalhadores adquirida fora do sistema formal. 
Tabela 10: Fatores competitivos determinantes para manter a capacidade competitivas das empresas.

\begin{tabular}{|c|c|c|c|c|c|c|c|c|c|c|c|c|c|c|c|}
\hline \multirow{2}{*}{ Fatores competitivos } & \multicolumn{5}{|c|}{ Micro } & \multicolumn{5}{|c|}{ Pequena } & \multicolumn{5}{|c|}{ Média } \\
\hline & Nula & Baixa & Média & Alta & Índice* & Nula & Baixa & Média & Alta & Índice* & Nula & Baixa & Média & Alta & Índice* \\
\hline \multirow{2}{*}{$\begin{array}{l}\text { 1. Qualidade da matéria-prima e } \\
\text { outros insumos }\end{array}$} & 5 & 2 & 8 & 30 & 0,79 & 0 & 0 & 0 & 1 & 1 & 0 & 0 & 0 & 1 & 1 \\
\hline & $11,10 \%$ & $4,40 \%$ & $17,80 \%$ & $66,70 \%$ & & $0,00 \%$ & $0,00 \%$ & $0,00 \%$ & $100,00 \%$ & & $0,00 \%$ & $0,00 \%$ & $0,00 \%$ & $100,00 \%$ & \\
\hline \multirow[t]{2}{*}{ 2. Qualidade da mão-de-obra } & 7 & 2 & 6 & 30 & 0,76 & 0 & 0 & 0 & 1 & 1 & 0 & 0 & 0 & 1 & 1 \\
\hline & $15,60 \%$ & $4,40 \%$ & $13,30 \%$ & $66,70 \%$ & & $0,00 \%$ & $0,00 \%$ & $0,00 \%$ & $100,00 \%$ & & $0,00 \%$ & $0,00 \%$ & $0,00 \%$ & $100,00 \%$ & \\
\hline \multirow[t]{2}{*}{ 3. Custo da mâo-de-obra } & 17 & 11 & 7 & 9 & 0,38 & 0 & 0 & 1 & 0 & 0,6 & 0 & 0 & 0 & 1 & 1 \\
\hline & $38,60 \%$ & $25,00 \%$ & $15,90 \%$ & $20,50 \%$ & & $0,00 \%$ & $0,00 \%$ & $100,00 \%$ & $0,00 \%$ & & $0,00 \%$ & $0,00 \%$ & $0,00 \%$ & $100,00 \%$ & \\
\hline \multirow{2}{*}{$\begin{array}{l}\text { 4. Nivel tecnológico dos } \\
\text { equipamentos }\end{array}$} & 22 & 10 & 8 & 5 & 0,28 & 0 & 0 & 0 & 1 & 1 & 1 & 0 & 0 & 0 & 0 \\
\hline & $48,90 \%$ & $22,20 \%$ & $17,80 \%$ & $11,10 \%$ & & $0,00 \%$ & $0,00 \%$ & $0,00 \%$ & $100,00 \%$ & & $100,00 \%$ & $0,00 \%$ & $0,00 \%$ & $0,00 \%$ & \\
\hline \multirow{2}{*}{$\begin{array}{l}\text { 5. Capacidade de introdução de } \\
\text { novos produtos/processos }\end{array}$} & 19 & 2 & 7 & 17 & 0,48 & 0 & 0 & 0 & 1 & 1 & 0 & 0 & 0 & 1 & 1 \\
\hline & $42,20 \%$ & $4,40 \%$ & $15,60 \%$ & $37,80 \%$ & & $0,00 \%$ & $0,00 \%$ & $0,00 \%$ & $100,00 \%$ & & $0,00 \%$ & $0,00 \%$ & $0,00 \%$ & $100,00 \%$ & \\
\hline \multirow[t]{2}{*}{ 6. Desenho e estilo dos produtos } & 4 & 2 & 5 & 34 & 0,84 & 0 & 0 & 1 & 0 & 0,6 & 0 & 0 & 0 & 1 & 1 \\
\hline & $8,90 \%$ & $4,40 \%$ & $11,10 \%$ & $75,60 \%$ & & $0,00 \%$ & $0,00 \%$ & $100,00 \%$ & $0,00 \%$ & & $0,00 \%$ & $0,00 \%$ & $0,00 \%$ & $100,00 \%$ & \\
\hline \multirow[t]{2}{*}{ 7. Estratégias de comercialização } & 15 & 4 & 10 & 15 & 0,5 & 0 & 0 & 0 & 1 & 1 & 0 & 0 & 0 & 1 & 1 \\
\hline & $34,10 \%$ & $9,10 \%$ & $22,70 \%$ & $34,10 \%$ & & $0,00 \%$ & $0,00 \%$ & $0,00 \%$ & $100,00 \%$ & & $0,00 \%$ & $0,00 \%$ & $0,00 \%$ & $100,00 \%$ & \\
\hline \multirow[t]{2}{*}{ 8. Qualidade do produto } & 5 & 2 & 4 & 34 & 0,82 & 0 & 0 & 0 & 1 & 1 & 0 & 0 & 0 & 1 & 1 \\
\hline & $11,10 \%$ & $4,40 \%$ & $8,90 \%$ & $75,60 \%$ & & $0,00 \%$ & $0,00 \%$ & $0,00 \%$ & $100,00 \%$ & & $0,00 \%$ & $0,00 \%$ & $0,00 \%$ & $100,00 \%$ & \\
\hline \multirow{2}{*}{$\begin{array}{l}\text { 9. Capacidade de atendimento } \\
\text { (volume e prazo) }\end{array}$} & 3 & 9 & 10 & 22 & 0.7 & 0 & 0 & 0 & 1 & 1 & 0 & 0 & 0 & 1 & 1 \\
\hline & $6,80 \%$ & $20,50 \%$ & $22,70 \%$ & $50,00 \%$ & & $0,00 \%$ & $0,00 \%$ & $0,00 \%$ & $100,00 \%$ & & $0,00 \%$ & $0,00 \%$ & $0,00 \%$ & $100,00 \%$ & \\
\hline \multirow[t]{2}{*}{ 10. Outra } & 23 & 0 & 1 & 4 & 0,16 & 1 & 0 & 0 & 0 & 0 & 1 & 0 & 0 & 0 & 0 \\
\hline & $82,10 \%$ & $0,00 \%$ & $3,60 \%$ & $14,30 \%$ & & $100,00 \%$ & $0,00 \%$ & $0,00 \%$ & $0,00 \%$ & & $100,00 \%$ & $0,00 \%$ & $0,00 \%$ & $0,00 \%$ & \\
\hline
\end{tabular}

Fonte: pesquisa de campo.

*Índice $=\left(0^{*} \mathrm{~N}^{\circ}\right.$ nulas $+0,3 * \mathrm{~N}^{\circ}$ baixas $+0,6 * \mathrm{~N}^{\circ}$ médias $+\mathrm{N}^{\mathrm{o}}$ altas $) /\left(\mathrm{N}^{\circ}\right.$ empresas no segmento). 


\section{DINÂMICA DE INOVAÇÃO}

A dinâmica da inovação é avaliada em função da geração e da transferência do conhecimento, o que está relacionado à "arte do ofício" do artesão, bem como das características, dos impactos e da constância dessas inovações nas empresas.

\subsection{A geração do conhecimento}

O processo de aprendizagem e de geração de conhecimento no âmbito das unidades produtivas dos artesãos está intimamente relacionado com a dominância das relações familiares no processo de trabalho. Isso influi diretamente na forma como é repassado o conhecimento tradicional, o conhecimento relativo às técnicas artesanais. Assim, em cerca de 60\% dos casos, o conhecimento artesanal é transmitido a familiares, amigos ou membros da comunidade onde o artesão habita; portanto, há sempre algum vínculo entre esses indivíduos, particularmente entre os familiares, que "seguem a tradição" da família (Tabela 11).

Figura 1: Processo de inovação da cerâmica de Icoaraci.

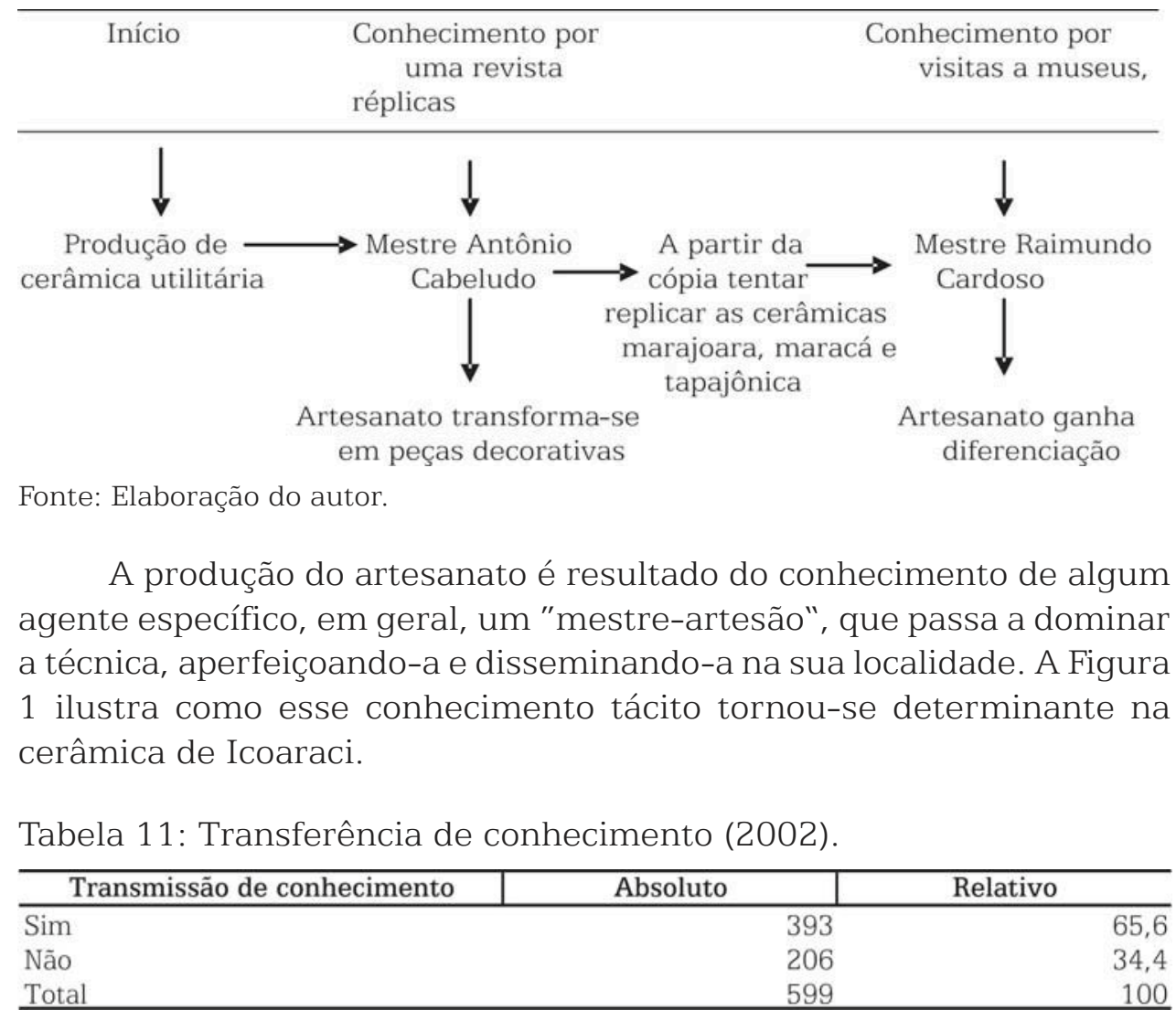

Fonte: SEBRAE; ACERTAR, 2002. 
Tabela 12: Para quem o conhecimento esta sendo repassado - 2002.

\begin{tabular}{l|r|r}
\hline \multicolumn{1}{c|}{ Origem } & Absoluto & \multicolumn{2}{c}{ Relativo } \\
\hline Família & 192 & 34,1 \\
Amigos & 140 & 24,6 \\
Comunidade & 85 & 15,1 \\
Alunos & 79 & 14 \\
Instituições (pública/privada) & 20 & 3,6 \\
Outros & 21 & 3,7 \\
Empregados & 20 & 3,6 \\
Cooperativa & 6 & 1,1 \\
Sindicato & 0 & 0 \\
Total & 599 & 100 \\
\hline
\end{tabular}

Fonte: SEBRAE; ACERTAR, 2002.

A capacidade de inovar, especialmente em um produto, refere-se particularmente à utilização de diferentes materiais em cada segmento específico. Um segmento diferenciado é o de artesanato em jóia, que tem utilizado diferentes fibras, como o curuá e o coco, além de sementes e frutos, juntamente com metais e gemas. O resultado dessa combinação efetivamente diferencia as jóias produzidas no Pará (RMB). A inovação nos desenhos, destacando-se a temática indígena ou amazônica, também se tem tornado um diferencial competitivo a considerar.

A inovação para o produtor tem, portanto, duplo caráter: inova-se na utilização de materiais e nos traços típicos que retratam a realidade do povo da região e sua relação com a natureza. Isso dá à inovação realizada um caráter eminentemente endógeno, fruto de um esforço criativo, na maioria dos casos, individual, procurando-se agregar valor ao artesanato produzido.

A inovação no processo, característica de técnicas rudimentares de produção, é muito pequena, quase sempre nasce da tentativa de solucionar um problema específico no processo produtivo, como a existência de impurezas na matéria-prima utilizada. Não é, portanto, um esforço contínuo de melhora, como é a inovação de produto, que por sua vez é novo para o mercado do produto. 
Tabela 13: Características da inovação.

\begin{tabular}{|c|c|c|c|}
\hline \multirow{2}{*}{ Descrição } & Micro & Pequena & Média \\
\hline & Sim & Sim & Sim \\
\hline 1. Inovaçōes de produto & $68,90 \%$ & $100,00 \%$ & $100,00 \%$ \\
\hline \multirow{2}{*}{$\begin{array}{l}\text { 1.1. Produto novo para a sua empresa, mas já existente no } \\
\text { mercado? }\end{array}$} & 24 & 1 & 0 \\
\hline & $68,60 \%$ & $100,00 \%$ & $0,00 \%$ \\
\hline \multirow[t]{2}{*}{ 1.2. Produto novo para o mercado nacional? } & 18 & 1 & 1 \\
\hline & $51,40 \%$ & $100,00 \%$ & $100,00 \%$ \\
\hline \multirow[t]{2}{*}{ 1.3. Produto novo para o mercado internacional? } & 8 & 1 & 1 \\
\hline & $24,20 \%$ & $100,00 \%$ & $100,00 \%$ \\
\hline 2. Inovações de processo & $26,70 \%$ & $100,00 \%$ & $0,00 \%$ \\
\hline \multirow{4}{*}{$\begin{array}{l}\text { 2.1. Processos tecnológicos novos para a sua empresa, mas já } \\
\text { existentes no setor? } \\
\text { 2.2. Processos tecnológicos novos para o setor de atuação? }\end{array}$} & 11 & 1 & 0 \\
\hline & $34,40 \%$ & $100,00 \%$ & $0,00 \%$ \\
\hline & 4 & 1 & 0 \\
\hline & $12,90 \%$ & $100,00 \%$ & $0,00 \%$ \\
\hline \multirow{5}{*}{$\begin{array}{l}\text { 3.1. Criação ou melhoria substancial, do ponto de vista } \\
\text { tecnológico, do modo de acondicionamento de produtos } \\
\text { (embalagem)? } \\
\text { 3.2. Inovações no desenho de produtos? }\end{array}$} & $51,10 \%$ & $100,00 \%$ & $100,00 \%$ \\
\hline & 8 & 1 & 1 \\
\hline & $26,70 \%$ & $100,00 \%$ & $100,00 \%$ \\
\hline & 23 & 1 & 1 \\
\hline & $71,90 \%$ & $100,00 \%$ & $100,00 \%$ \\
\hline \multicolumn{3}{|l|}{ 4. Realização de mudanças organizacionais (inovações } & $100,00 \%$ \\
\hline \multirow[t]{2}{*}{ 4.1. Implementação de técnicas avançadas de gestão? } & 3 & 1 & 0 \\
\hline & $10,00 \%$ & $100,00 \%$ & $0,00 \%$ \\
\hline \multirow{2}{*}{$\begin{array}{l}\text { 4.2. Implementação de significativas mudanças na estrutura } \\
\text { organizacional? }\end{array}$} & 6 & 1 & 1 \\
\hline & $20,00 \%$ & $100,00 \%$ & $100,00 \%$ \\
\hline \multirow{2}{*}{$\begin{array}{l}\text { 4.3. Mudanças significativas nos conceitos e/ou na práticas de } \\
\text { marketing? }\end{array}$} & 6 & 1 & 1 \\
\hline & $20,00 \%$ & $100,00 \%$ & $100,00 \%$ \\
\hline \multirow{2}{*}{$\begin{array}{l}\text { 4.4. Mudanças significativas nos conceitos e/ou nas práticas de } \\
\text { comercialização? }\end{array}$} & 7 & 1 & 1 \\
\hline & $23,30 \%$ & $100,00 \%$ & $100,00 \%$ \\
\hline \multirow{2}{*}{$\begin{array}{l}\text { 4.5. Implementação de novos métodos e gerenciamento, visando } \\
\text { a atender normas de certificação (ISO 9000, ISO 14000, etc)? }\end{array}$} & 1 & 1 & 1 \\
\hline & $3,80 \%$ & $100,00 \%$ & $100,00 \%$ \\
\hline
\end{tabular}

Fonte: pesquisa de campo.

${ }^{*}$ Índice $=\left(\mathrm{N}^{\circ}\right.$ empresas com pelo menos um sim) $/$ ( $\mathrm{N}^{\circ}$ empresas no segmento).

A Tabela 14 mostra que a inovação de processo e outros tipos de inovação foram implementados mais nas empresas de maior porte. 
Tabela 14: Impacto da inovação

\begin{tabular}{|c|c|c|c|c|c|c|c|c|c|c|}
\hline \multirow{2}{*}{ Descrição } & \multicolumn{5}{|c|}{ Micro } & \multicolumn{5}{|c|}{ Pequena } \\
\hline & Nula & Baixa & Média & Alta & Indice* & Nula & Baixa & Média & Alta & Indice* \\
\hline \multirow[t]{2}{*}{ 1. Aumento da produtividade da empresa } & 3 & 3 & 11 & 14 & 0,69 & 0 & 0 & 0 & 1 & 1 \\
\hline & $9,70 \%$ & $9,70 \%$ & $35,50 \%$ & $45,20 \%$ & & $0,00 \%$ & $0,00 \%$ & $0,00 \%$ & $100,00 \%$ & \\
\hline \multirow[t]{2}{*}{ 2. Ampliação da gama de produtos ofertados } & 1 & 2 & 13 & 18 & 0,78 & 0 & 0 & 0 & 1 & 1 \\
\hline & $2,90 \%$ & $5,90 \%$ & $38,20 \%$ & $52,90 \%$ & & $0,00 \%$ & $0,00 \%$ & $0,00 \%$ & $100,00 \%$ & \\
\hline \multirow[t]{2}{*}{ 3. Aumento da qualidade dos produtos } & 1 & 10 & 3 & 16 & 0,69 & 0 & 0 & 0 & 1 & 1 \\
\hline & $3,30 \%$ & $33,30 \%$ & $10,00 \%$ & $53,30 \%$ & & $0,00 \%$ & $0,00 \%$ & $0,00 \%$ & $100,00 \%$ & \\
\hline \multirow{2}{*}{$\begin{array}{l}\text { 4. Manutenção da empresa nos mercados de } \\
\text { atuação }\end{array}$} & 3 & 3 & 13 & 13 & 0,68 & 0 & 0 & 0 & 1 & 1 \\
\hline & $9,40 \%$ & $9,40 \%$ & $40,60 \%$ & $40,60 \%$ & & $0,00 \%$ & $0,00 \%$ & $0,00 \%$ & $100,00 \%$ & \\
\hline \multirow{2}{*}{$\begin{array}{l}\text { 5. Aumento da participação no mercado interno } \\
\text { da empresa }\end{array}$} & 3 & 6 & 11 & 11 & 0,63 & 0 & 0 & 0 & 1 & 1 \\
\hline & $9,70 \%$ & $19,40 \%$ & $35,50 \%$ & $35,50 \%$ & & $0,00 \%$ & $0,00 \%$ & $0,00 \%$ & $100,00 \%$ & \\
\hline \multirow{2}{*}{$\begin{array}{l}\text { 6. Aumento da participação no mercado externo } \\
\text { da empresa }\end{array}$} & 9 & 6 & 7 & 8 & 0,47 & 0 & 0 & 0 & 1 & 1 \\
\hline & $30,00 \%$ & $20,00 \%$ & $23,30 \%$ & $26,70 \%$ & & $0,00 \%$ & $0,00 \%$ & $0,00 \%$ & $100,00 \%$ & \\
\hline \multirow{2}{*}{ 7. Abertura de novos mercados para a empresa } & 8 & 10 & 5 & 6 & 0,41 & 0 & 0 & 0 & 1 & 1 \\
\hline & $27,60 \%$ & $34,50 \%$ & $17,20 \%$ & $20,70 \%$ & & $0,00 \%$ & $0,00 \%$ & $0,00 \%$ & $100,00 \%$ & \\
\hline \multirow[t]{2}{*}{ 8. Redução de custos do trabalho } & 16 & 5 & 6 & 4 & 0,29 & 0 & 0 & 0 & 1 & 1 \\
\hline & $51,60 \%$ & $16,10 \%$ & $19,40 \%$ & $12,90 \%$ & & $0,00 \%$ & $0,00 \%$ & $0,00 \%$ & $100,00 \%$ & \\
\hline \multirow[t]{2}{*}{ 9. Redução de custos de insumos } & 19 & 3 & 7 & 2 & 0,23 & 0 & 0 & 1 & 0 & 0,6 \\
\hline & $61,30 \%$ & $9,70 \%$ & $22,60 \%$ & $6.50 \%$ & & $0,00 \%$ & $0,00 \%$ & $100,00 \%$ & $0,00 \%$ & \\
\hline \multirow[t]{2}{*}{ 10. Redução do consumo de energia } & 25 & 0 & 4 & 1 & 0,11 & 0 & 0 & 1 & 0 & 0,6 \\
\hline & $83,30 \%$ & $0,00 \%$ & $13,30 \%$ & $3,30 \%$ & & $0,00 \%$ & $0,00 \%$ & $100,00 \%$ & $0,00 \%$ & \\
\hline \multirow{6}{*}{$\begin{array}{l}\text { 11. Enquadramento em regulações e normas } \\
\text { padrão relativas ao mercado interno } \\
\text { 12. Enquadramento em regulações e normas } \\
\text { padrão relativas ao mercado externo } \\
\text { 13. Redução do impacto sobre o meio ambiente }\end{array}$} & 21 & 2 & 1 & 3 & 0,16 & 0 & 0 & 1 & 0 & 0,6 \\
\hline & $77,80 \%$ & $7,40 \%$ & $3,70 \%$ & $11,10 \%$ & & $0,00 \%$ & $0,00 \%$ & $100,00 \%$ & $0,00 \%$ & \\
\hline & 22 & 1 & 1 & 3 & 0,14 & 0 & 0 & 1 & 0 & 0,6 \\
\hline & $81,50 \%$ & $3,70 \%$ & $3,70 \%$ & $11,10 \%$ & & $0,00 \%$ & $0,00 \%$ & $100,00 \%$ & $0,00 \%$ & \\
\hline & 22 & 0 & 1 & 2 & 0,1 & 0 & 0 & 1 & 0 & 0,6 \\
\hline & $88,00 \%$ & $0,00 \%$ & $4,00 \%$ & $8,00 \%$ & & $0,00 \%$ & $0,00 \%$ & $100,00 \%$ & $0,00 \%$ & \\
\hline
\end{tabular}

Fonte: pesquisa de campo.

*Índice $=\left(0^{*} \mathrm{~N}^{\mathrm{O}}\right.$ nulas $+0,3 * \mathrm{~N}^{\circ}$ baixas $+0,6 * \mathrm{~N}^{\mathrm{O}}$ médias $+\mathrm{N}^{\mathrm{o}}$ altas $) /\left(\mathrm{N}^{\circ}\right.$ empresas no segmento $)$. 
A inovação permite ao mesmo tempo a) a ampliação da gama de produtos, b) o aumento da qualidade e c) a manutenção ou ampliação da participação do produto de mercado. A preocupação com a qualidade do produto é grande em todos os segmentos e constitui o principal elemento motivador da inovação perseguida. Isso é constatado em todas as empresas, independentemente de seu porte.

Os resultados apresentados na Tabela 15, relativos à constância de inovação, podem levar a uma análise contraditória do que foi dito acima, pelo menos no que diz respeito às microempresas artesanais. Isso porque a inovação - embora, quanto ao produto, tenha caráter contínuo - não nasce de um departamento específico ou de pesquisa e desenvolvimento ( $\mathrm{P} \& \mathrm{D}$ ) formal na empresa. Assim, esse item e os demais foram considerados baixos para as unidades pesquisadas. Para as duas empresas de porte pequeno e médio, a rotina de inovações é mais destacada, no que diz respeito a projetos industriais ligados aos novos produtos, bem como à implantação de programas de treinamento.

Para as microempresas, a informação adquirida pela experiência dentro da empresa, nas atividades de produção, é muito importante; entretanto, assume grande importância, também, a informação obtida das externalidades geradas por outros agentes, como clientes e mesmo outras empresas, especialmente em eventos, como feiras e exposições. As empresas de maior porte conseguem absorver informação mais intensamente de outras fontes, como universidades e associações empresariais. 
Tabela 15: Constância da inovação nas microempresas pesquisadas.

\begin{tabular}{|c|c|c|c|c|}
\hline \multirow{2}{*}{ Descrição } & \multicolumn{4}{|c|}{ Micro } \\
\hline & Não desenvolveu & Rotineiramente & Ocasionalmente & Índice ${ }^{*}$ \\
\hline \multirow[t]{2}{*}{ 1. Pesquisa e desenvolvimento (P\&D) na sua empresa } & 20 & 2 & 4 & 0,15 \\
\hline & $76,90 \%$ & $7,70 \%$ & $15,40 \%$ & \\
\hline \multirow{2}{*}{ 2. Aquisição externa de P\&D } & 17 & 6 & 3 & 0,29 \\
\hline & $65,40 \%$ & $23,10 \%$ & $11,50 \%$ & \\
\hline \multirow{2}{*}{$\begin{array}{l}\text { 3. Aquisição de máquinas e equipamentos que implicaram } \\
\text { significativas melhorias tecnológicas de produtos/processos ou } \\
\text { que estão associados aos novos produtos/processos }\end{array}$} & 19 & 5 & 3 & 0,24 \\
\hline & $70,40 \%$ & $18,50 \%$ & $11,10 \%$ & \\
\hline \multirow{2}{*}{$\begin{array}{l}\text { 4. Aquisição de outras tecnologias (softwares, licenças ou } \\
\text { acordos de transferência de tecnologias, como patentes, marcas, } \\
\text { segredos industriais) }\end{array}$} & 24 & 2 & 0 & 0,08 \\
\hline & $92,30 \%$ & $7,70 \%$ & $0,00 \%$ & \\
\hline \multirow{2}{*}{$\begin{array}{l}\text { 5. Projeto industrial ou desenho industrial associados a } \\
\text { produtos/processos tecnologicamente novos ou } \\
\text { significativamente melhorados }\end{array}$} & 24 & 3 & 0 & 0,11 \\
\hline & $88,90 \%$ & $11,10 \%$ & $0,00 \%$ & \\
\hline \multirow{2}{*}{$\begin{array}{l}\text { 6. Programa de treinamento destinado à introdução de } \\
\text { produtos/processos tecnologicamente novos ou } \\
\text { significativamente melhorados }\end{array}$} & 19 & 6 & 1 & 0,25 \\
\hline & $73,10 \%$ & $23,10 \%$ & $3,80 \%$ & \\
\hline \multirow{2}{*}{$\begin{array}{l}\text { 7. Programas de gestão da qualidade ou de modernização } \\
\text { organizacional, como: qualidade total, reengenharia de } \\
\text { processos administrativos, desverticalização do processo } \\
\text { produtivo, métodos de just in time, etc }\end{array}$} & 26 & 0 & 0 & 0 \\
\hline & $100,00 \%$ & $0,00 \%$ & $0,00 \%$ & \\
\hline \multirow{2}{*}{$\begin{array}{l}\text { 8. Novas formas de comercialização e distribuição para o } \\
\text { mercado de produtos novos ou significativamente melhorados }\end{array}$} & 22 & 3 & 1 & 0,13 \\
\hline & $84,60 \%$ & $11,50 \%$ & $3,80 \%$ & \\
\hline
\end{tabular}

Fonte: pesquisa de campo.

* Índice $=\left(0^{*} \mathrm{~N}^{\circ}\right.$ não desenvolveu $+0,5^{*} \mathrm{~N}^{\circ}$ ocasionalmente $+\mathrm{N}^{\circ}$ rotineiramente) $/$ ( $\mathrm{N}^{\circ}$ empresas no segmento). 


\subsection{Treinamento e capacitação}

O treinamento depende da segmentação da atividade. Assim, enquanto para alguns segmentos o treinamento como uma atividade regular não existiu, para outros segmentos, por assim dizer, mais profissionalizados, como o segmento de jóias, tem sido importante.

Tabela 16: Treinamento nas microempresas artesanais.

\begin{tabular}{l|ccc|c|c}
\hline \multirow{2}{*}{ Descrição } & \multicolumn{5}{c}{ Micro } \\
\cline { 2 - 6 } & Nula & Baixa & Média & Alta & Índice $^{*}$ \\
\hline 1. Treinamento na empresa & 20 & 1 & 10 & 12 & 0,43 \\
& $46,50 \%$ & $2,30 \%$ & $23,30 \%$ & $27,90 \%$ & \\
\hline 2. Treinamento em cursos técnicos & 19 & 4 & 6 & 15 & 0,45 \\
realizados no arranjo & $43,20 \%$ & $9,10 \%$ & $13,60 \%$ & $34,10 \%$ & \\
\hline 3. Treinamento em cursos técnicos fora & 24 & 6 & 5 & 7 & 0,28 \\
do arranjo & $57,10 \%$ & $14,30 \%$ & $11,90 \%$ & $16,70 \%$ & \\
\hline 4. Estágios em empresas fornecedoras ou & 41 & 1 & 1 & 0 & 0,02 \\
clientes & $95,30 \%$ & $2,30 \%$ & $2,30 \%$ & $0,00 \%$ & \\
\hline 5. Estágios em empresas do grupo & 40 & 3 & 0 & 0 & 0,02 \\
& $93,00 \%$ & $7,00 \%$ & $0,00 \%$ & $0,00 \%$ & \\
\hline 6. Contratação de técnicos/engenheiros de & 35 & 5 & 1 & 2 & 0,1 \\
outras empresas do arranjo & $81,40 \%$ & $11,60 \%$ & $2,30 \%$ & $4,70 \%$ & \\
\hline 7. Contratação de técnicos/engenheiros de & 43 & 0 & 0 & 0 & 0 \\
empresas fora do arranjo & $100,00 \%$ & $0,00 \%$ & $0,00 \%$ & $0,00 \%$ & \\
\hline 8. Absorção de formandos dos cursos & 37 & 2 & 2 & 2 & 0,09 \\
universitários localizados no arranjo ou & & & & 2 & \\
perto & $86,00 \%$ & $4,70 \%$ & $4,70 \%$ & $4,70 \%$ & \\
\hline 9. Absorção de formandos dos cursos & 34 & 4 & 3 & 1 & 0,1 \\
técnicos localizados no arranjo ou perto & $81,00 \%$ & $9,50 \%$ & $7,10 \%$ & $2,40 \%$ & \\
\hline
\end{tabular}

Fonte: pesquisa de campo.

*Índice $=\left(0^{*} \mathrm{~N}^{\circ}\right.$ nulas $+0,3 * \mathrm{~N}^{\circ}$ baixas $+0,6 * \mathrm{~N}^{\circ}$ médias $+\mathrm{N}^{\circ}$ altas $) /\left(\mathrm{N}^{\circ}\right.$ empresas no segmento).

O treinamento não é realizado somente dentro da unidade produtiva, mas dentro do arcabouço institucional criado para tanto. O índice para as microempresas artesanais não ultrapassa 0,5 para todos os itens, devido a diferenciação dos treinamentos para os tipos de atividades. Entretanto, para as pequenas e médias, atinge 1 para os dois primeiros itens: treinamento na empresa e treinamento em cursos técnicos realizados no arranjo.

\section{COOPERAÇÃO}

A cooperação é bastante importante nas empresas artesanais, especialmente nas microempresas. De fato, as associações que desempenham papel de coordenação em alguns espaços físicos importantes, como a COMIP, no Mercado de São Braz, a ARTEPAM, na 
feira do artesanato na praça de República, a COSAPA, no bairro do Paracuri em Icoaraci, além daquelas de natureza pública, cuja coordenação é exercida pelo Estado, têm criado maiores oportunidades, por meio da venda conjunta de produtos. Desempenham ainda um papel aglutinador em outras formas de cooperação, na defesa de reivindicações comuns, na tentativa de obtenção de financiamento, na participação conjunta em feiras e na capacitação de recursos humanos.

Tabela 17: Realização de cooperação pelas empresas.

\begin{tabular}{lcccc}
\hline \multicolumn{1}{c}{ Tamanho da empresa } & Sim & Não & Total \\
\hline 1. Micro & 36 & 8 & 44 \\
& $81,80 \%$ & $18,20 \%$ & $100,00 \%$ \\
\hline 2. Pequena & 1 & 0 & 1 \\
& $100,00 \%$ & $0,00 \%$ & $100,00 \%$ \\
\hline 3. Média & 1 & 0 & 1 \\
& $100,00 \%$ & $0,00 \%$ & $100,00 \%$ \\
\hline 4. Grande & 0 & 0 & 0 \\
& $0,00 \%$ & $0,00 \%$ & $0,00 \%$ \\
\hline
\end{tabular}

Fonte: pesquisa de campo.

As formas de cooperação têm sido um diferencial da atividade, e o Estado e as associações têm desempenhado um papel destacado em alguns segmentos. O Estado tem sido responsável principalmente por conscientizar os artesãos da necessidade de atender as demandas do mercado. Para tanto, tem promovido programas de capacitação e treinamento, bem como tem servido de coordenador nas experiências de associativismo. Isso inclui a criação de uma infra-estrutura física que permite a transmissão de conhecimento e o treinamento, assim como a comercialização de produtos. Espaços físicos dessa natureza são, principalmente, o Espaço São José Liberto e a Fundação Curro Velho. Além disso, o Estado tem intervindo no sentido de reforçar certos elos considerados frágeis na cadeia produtiva. Assim, a experiência do São José Liberto como Pólo Joalheiro é exemplar nessa direção: alia capacitação a coordenação e, ao mesmo tempo, introduz mecanismos para assegurar, por exemplo, o fornecimento de matérias-primas, oriundas especialmente de Itaituba, Floresta do Araguaia e Parauapebas.

A Tabela 18 permite verificar que mais de 80\% das unidades exercem algum tipo de atividade cooperativa. A presença de institutos de pesquisa e das universidades ainda é inexpressiva. A presença do SEBRAE como órgão de apoio e promoção é reforçada. 
Tabela 18: Parceiros na cooperação nas microempresas.

\begin{tabular}{|c|c|c|c|c|c|}
\hline \multirow{2}{*}{ Agentes } & \multicolumn{5}{|c|}{ Micro } \\
\hline & Nula & Baixa & Média & Alta & Índice* \\
\hline \multicolumn{6}{|l|}{ 1. Empresas } \\
\hline 1.1. Outras empresas dentro do grupo & 12 & 5 & ${ }^{7}$ & 1 & 0,15 \\
\hline 1.2. Empresas associadas (joint ventures) & $\begin{array}{c}24 \\
96,00 \%\end{array}$ & $\begin{array}{c}1 \\
4,00 \%\end{array}$ & $\begin{array}{c}0 \\
0,00 \%\end{array}$ & $\begin{array}{c}0 \\
0,00 \%\end{array}$ & 0,01 \\
\hline $\begin{array}{l}\text { 1.3. Fornecedores de insumos (equipamentos, } \\
\text { materiais, componentes e softwares) }\end{array}$ & 6 & 3 & 10 & 7 & 0,31 \\
\hline & $23,10 \%$ & $11,50 \%$ & $38,50 \%$ & $26,90 \%$ & \\
\hline 1.4. Clientes & $\begin{array}{c}5 \\
18,50 \%\end{array}$ & $\begin{array}{c}0 \\
0,00 \%\end{array}$ & $\begin{array}{c}9 \\
33,30 \%\end{array}$ & $\begin{array}{c}13 \\
48,10 \%\end{array}$ & 0,41 \\
\hline 1.5. Concorrentes & $\begin{array}{c}5 \\
13,50 \%\end{array}$ & $\begin{array}{c}2 \\
5,40 \%\end{array}$ & $\begin{array}{c}4 \\
10,80 \%\end{array}$ & $\begin{array}{c}26 \\
70,30 \%\end{array}$ & 0,64 \\
\hline 1.6. Outras empresas do setor & $\begin{array}{c}10 \\
41,70 \%\end{array}$ & $\begin{array}{c}9 \\
37,50 \%\end{array}$ & $\begin{array}{c}3 \\
12,50 \%\end{array}$ & $\begin{array}{c}2 \\
8,30 \%\end{array}$ & 0,14 \\
\hline 1.7. Empresas de consultoria & $\begin{array}{c}20 \\
87,00 \%\end{array}$ & $\begin{array}{c}0 \\
0,00 \%\end{array}$ & $\begin{array}{c}2 \\
8,70 \%\end{array}$ & $\begin{array}{c}1 \\
4,30 \%\end{array}$ & 0,05 \\
\hline \multicolumn{6}{|l|}{ 2. Universidades e institutos de pesquisa } \\
\hline 2.1. Universidades & $\begin{array}{c}9 \\
36,00 \%\end{array}$ & $\begin{array}{c}8 \\
32,00 \%\end{array}$ & $\begin{array}{c}4 \\
16,00 \%\end{array}$ & $\begin{array}{c}4 \\
16,00 \%\end{array}$ & 0,2 \\
\hline 2.2. Institutos de pesquisa & $\begin{array}{c}10 \\
43,50 \%\end{array}$ & $\begin{array}{c}1 \\
4,30 \%\end{array}$ & $\begin{array}{c}9 \\
39,10 \%\end{array}$ & $\begin{array}{c}3 \\
13,00 \%\end{array}$ & 0,19 \\
\hline 2.3. Centros de capacitação profissional de & 14 & 1 & 5 & 5 & 0,18 \\
\hline assistência técnica e de manutenção & $56,00 \%$ & $4,00 \%$ & $20,00 \%$ & $20,00 \%$ & \\
\hline $\begin{array}{l}\text { 2.4. Instituições de testes, ensaios e } \\
\text { certificações }\end{array}$ & $\begin{array}{c}19 \\
90,50 \% \\
\end{array}$ & $\begin{array}{c}0 \\
0,00 \% \\
\end{array}$ & $\begin{array}{c}2 \\
9,50 \% \\
\end{array}$ & $\begin{array}{c}0 \\
0,00 \% \\
\end{array}$ & 0,03 \\
\hline \multicolumn{6}{|l|}{ 3. Outros agentes } \\
\hline 3.1. Representação & $\begin{array}{c}17 \\
68,00 \%\end{array}$ & $\begin{array}{c}2 \\
8,00 \%\end{array}$ & $\begin{array}{c}3 \\
12,00 \%\end{array}$ & $\begin{array}{c}3 \\
12,00 \%\end{array}$ & 0,12 \\
\hline 3.2. Entidades sindicais & $\begin{array}{c}13 \\
50,00 \%\end{array}$ & $\begin{array}{c}3 \\
11,50 \%\end{array}$ & $\begin{array}{c}9 \\
34,60 \%\end{array}$ & $\begin{array}{c}1 \\
3,80 \%\end{array}$ & 0,16 \\
\hline 3.3. Órgãos de apoio e promoção & $\begin{array}{c}9 \\
32,10 \%\end{array}$ & $\begin{array}{c}1 \\
3,60 \%\end{array}$ & $\begin{array}{c}4 \\
14,30 \%\end{array}$ & $\begin{array}{c}14 \\
50,00 \%\end{array}$ & 0,37 \\
\hline 3.4. Agentes financeiros & $\begin{array}{c}13 \\
44,80 \%\end{array}$ & $\begin{array}{c}2 \\
6,90 \%\end{array}$ & $\begin{array}{c}1 \\
3,40 \%\end{array}$ & $\begin{array}{c}13 \\
44,80 \%\end{array}$ & 0,32 \\
\hline
\end{tabular}

Fonte: pesquisa de campo.

${ }^{*}$ Índice $=\left(0^{*} \mathrm{~N}^{\circ}\right.$ nulas $+0,3 * \mathrm{~N}^{\circ}$ baixas $+0,6 * \mathrm{~N}^{\circ}$ médias $+\mathrm{N}^{\circ}$ altas $) /\left(\mathrm{N}^{\circ}\right.$ empresas no segmento).

\subsection{Associações}

A associação desempenha um papel de grande relevância, especialmente como interlocutor dos artesãos junto aos órgãos públicos. Diversas associações foram criadas pelos próprios produtores, destacando-se a Associação dos Artesãos da Feira do Artesanato da Praça da República (AAFA), a Cooperativa dos Microprodutores e Artesãos da Área Metropolitana de Belém (COMIP), a Cooperativa de Artesãos de Icoaraci (COART), o Conselho Superior de Artesanato do Pará (COSAPA), com 80 associados, e a Sociedade dos Amigos de Icoaraci (SOAMI) - as três últimas de Icoaraci. 
A Associação dos Artesãos e Expositores do Pará e Amazônia (ARTEPAM) deu origem à Associação dos Artesãos da Feira do Artesanato da Praça da República (AAFA). O Principal objetivo da AAFA é coordenar a feira do artesanato da praça da República, que se mantém há 18 anos.

Todos os associados da AAFA são expositores na praça da República, mas participam de outras feiras na cidade, de feiras pontuais em todo o Brasil e da Feira Nacional do Artesanato.

A Feira possui 260 artesãos associados, sendo 40 produtores de artesanato regional ${ }^{2}$. Há 274 barracas, que se instalam no perímetro que vai da rua da Paz até o fim do anfiteatro. Na feira existe segurança contratada para assegurar o espaço.

A AAFA, formada por seis diretorias e três comissões (com cinco membros), realiza duas assembléias ordinárias por ano. De acordo com o estatuto da AAFA, são tolerados até 3 meses de inadimplência.

As principais dificuldades enfrentadas são: falta de segurança pública na praça, falta de ordenamento do espaço público (presença de vendedores ambulantes) e dificuldade de acesso a financiamento.

\subsection{A cooperação coordenada pelo Estado}

Algumas experiências de cooperação, coordenadas pelo Estado têm sido bem-sucedidas, por serem capazes de promover a articulação da cadeia e dos seus agentes, de criar espaços comuns de capacitação e comercialização de produtos e de oferecer aos artesãos associados economia de escopo e de escala. Duas experiências em espaços culturais devem ser destacadas: a Fundação Curro Velho (FCV) e o Espaço São José Liberto.

\subsubsection{Fundação Curro Velho}

A Fundação Curro Velho conta com dois prédios: a Casa da Linguagem e o prédio do Curro Velho, onde funciona o Núcleo de Produção. Eram ofertadas 54 oficinas por mês durante oito meses por ano, totalizando 450 oficinas por ano. Como critério de seleção para participação nas oficinas, é dada preferência a jovens em situação de risco e também é analisado o desempenho do participante ao longo do ano, o que serve de referência para a seleção no ano seguinte.

Os alunos matriculados em escolas públicas não pagam pelas oficinas, e os outros interessados pagam uma taxa de matrícula de $\mathrm{R} \$ 15,00$ (quinze reais). Para que isso funcione normalmente, o calendário de oficinas do Curro Velho é "casado" com o calendário da Secretaria Estadual de Educação (SEDUC). Anualmente a Fundação realiza três eventos especiais:

\footnotetext{
${ }^{2}$ Em verdade, apenas 40 produtores, como citado vendem artesanatos, o restante é basicamente de comidas típicas ou não da região.
} 
a) em fevereiro, ocorre o desfile de uma escola de samba completa (com carro abre-alas, comissão de frente, bateria, ala das baianas e samba enredo próprio), composta de 360 integrantes;

b) no mês de junho, há uma festa junina com a participação de 340 pessoas;

c) em dezembro, é comemorado o Natal, com a participação de 220 pessoas.

O Núcleo de Produção da FCV já existe há 10 anos e atualmente trabalha com seis atividades principais: papel, cerâmica, marcenaria, caixeteria e encadernação, reprodução de imagens e cestaria (cujo público-alvo é principalmente pessoas mais idosas, que se tornam agentes multiplicadores e podem vir a ser instrutores em outras oficinas da Fundação).

De cada oficina, participam 15 alunos, o que corresponde a um total de 90 jovens. Esses jovens são escolhidos levando-se em conta o seu desempenho nas oficinas de que participaram. Alguns alunos recebem uma bolsa de auxílio de 1/2 salário mínimo durante dois meses pelo Programa de Fomento à Cultura da Paz (Pró-Paz).

\subsubsection{Espaço São José Liberto - Pólo Joalheiro (Casa do Artesão)}

O espaço São José Liberto surgiu em 2001, fruto de uma série de articulações entre diversos órgãos como Serviço Nacional de Aprendizagem Industrial (SENAI), SEBRAE, Secretaria Executiva de Indústria, Comércio e Mineração (SEICOM), Secretaria Executiva da Ciência, Tecnologia e Meio Ambiente (SECTAM), Secretaria Executiva de Trabalho e Promoção Social (SETEPS) e entidades representativas dos produtores (jóias), com o intuito de verticalizar a cadeia produtiva de gemas e jóias do Estado do Pará. Em 2002, surge a Associação São José Liberto, de cunho privado, sem fins lucrativos, que passa a incorporar o Pólo Joalheiro.

O espaço São José Liberto abarca seis lojas de jóias, cada uma com duas empresas, e mais uma que funciona em regime de consignação com produtores autônomos, hoje 42.

Por ser um espaço comum, existe um conjunto de regras de administração que têm de ser seguidas por todos os participantes. Assim, por exemplo, 70\% das peças do produtor devem ter design amazônico. Além disso, como um diferencial para os produtores que integram o Pólo Joalheiro, exige-se a busca da qualidade, em todas as fases do processo.

No espaço São José Liberto, funciona também a Escola de Formação Profissional em Joalheria, de cunho privado, de responsabilidade da Rahma Gemas e Jóias, que oferece cursos de joalheria básica e de fundição de jóias em cera perdida.

As formas de cooperação (Tabela 19) são apontadas, especialmente pelas microempresas, como mecanismos eficientes para a obtenção de financiamento conjunto, como também para a venda conjunta de produtos, incluindo a participação em eventos comerciais, como feiras. 
Tabela 19: Formas de cooperação.

\begin{tabular}{|c|c|c|c|c|c|c|c|c|c|c|c|c|c|c|c|}
\hline \multirow{2}{*}{ Descrição } & \multicolumn{5}{|c|}{ Micro } & \multicolumn{5}{|c|}{ Pequena } & \multicolumn{5}{|c|}{ Média } \\
\hline & Nula & Baixa & Média & Alta & Índice* & Nula & Baixa & Média & Alta & Índice* & Nula & Baixa & Média & Alta & Índice* \\
\hline \multirow{2}{*}{$\begin{array}{l}\text { 1. Compra de insumos } \\
\text { e equipamentos }\end{array}$} & 21 & 8 & 3 & 7 & 0,25 & 0 & 1 & 0 & 0 & 0,3 & 1 & 0 & 0 & 0 & 0 \\
\hline & $53,80 \%$ & $20,50 \%$ & $7,70 \%$ & $17,90 \%$ & & $0,00 \%$ & $100,00 \%$ & $0,00 \%$ & $0,00 \%$ & & $100,00 \%$ & $0,00 \%$ & $0,00 \%$ & $0,00 \%$ & \\
\hline \multirow{2}{*}{$\begin{array}{l}\text { 2. Venda conjunta de } \\
\text { produtos }\end{array}$} & 8 & 1 & 6 & 24 & 0,62 & 0 & 0 & 0 & 1 & 1 & 0 & 0 & 1 & 0 & $\overline{0,6}$ \\
\hline & $20,50 \%$ & $2,60 \%$ & $15,40 \%$ & $61,50 \%$ & & $0,00 \%$ & $0,00 \%$ & $0,00 \%$ & $100,00 \%$ & & $0,00 \%$ & $0,00 \%$ & $100,00 \%$ & $0,00 \%$ & \\
\hline \multirow{2}{*}{$\begin{array}{l}\text { 3. Desenvolvimento de } \\
\text { produtos e processos }\end{array}$} & 18 & 1 & 9 & 11 & 0,37 & 0 & 0 & 1 & 0 & 0,6 & 1 & 0 & 0 & 0 & 0 \\
\hline & $46,20 \%$ & $2,60 \%$ & $23,10 \%$ & $28,20 \%$ & & $0,00 \%$ & $0,00 \%$ & $100,00 \%$ & $0,00 \%$ & & $100,00 \%$ & $0,00 \%$ & $0,00 \%$ & $0,00 \%$ & \\
\hline \multirow{2}{*}{$\begin{array}{l}\text { 4. Design e estilo de } \\
\text { produtos }\end{array}$} & 17 & 4 & 10 & 8 & 0,34 & 0 & 0 & 0 & 1 & 1 & 0 & 0 & 1 & 0 & 0,6 \\
\hline & $43,60 \%$ & $10,30 \%$ & $25,60 \%$ & $20,50 \%$ & & $0,00 \%$ & $0,00 \%$ & $0,00 \%$ & $100,00 \%$ & & $0,00 \%$ & $0,00 \%$ & $100,00 \%$ & $0,00 \%$ & \\
\hline \multirow{2}{*}{$\begin{array}{l}\text { 5. Capacitação de } \\
\text { recursos humanos }\end{array}$} & 17 & 3 & 8 & 11 & 0,37 & 0 & 0 & 0 & 1 & 1 & 0 & 0 & 1 & 0 & 0,6 \\
\hline & $43,60 \%$ & $7,70 \%$ & $20,50 \%$ & $28,20 \%$ & & $0,00 \%$ & $0,00 \%$ & $0,00 \%$ & $100,00 \%$ & & $0,00 \%$ & $0,00 \%$ & $100,00 \%$ & $0,00 \%$ & \\
\hline \multirow{2}{*}{$\begin{array}{l}\text { 6. Obtençāo de } \\
\text { financiamento }\end{array}$} & 12 & 1 & 5 & 21 & 0,54 & 0 & 1 & 0 & 0 & 0,3 & 0 & 0 & 0 & 1 & 1 \\
\hline & $30,80 \%$ & $2,60 \%$ & $12,80 \%$ & $53,80 \%$ & & $0,00 \%$ & $100,00 \%$ & $0,00 \%$ & $0,00 \%$ & & $0,00 \%$ & $0,00 \%$ & $0,00 \%$ & $100,00 \%$ & \\
\hline \multirow[t]{2}{*}{ 7. Reivindicações } & 12 & 10 & 2 & 15 & 0,43 & 0 & 0 & 1 & 0 & 0,6 & 0 & 0 & 0 & 1 & 1 \\
\hline & $30,80 \%$ & $25,60 \%$ & $5,10 \%$ & $38,50 \%$ & & $0,00 \%$ & $0,00 \%$ & $100,00 \%$ & $0,00 \%$ & & $0,00 \%$ & $0,00 \%$ & $0,00 \%$ & $100,00 \%$ & \\
\hline \multirow{2}{*}{$\begin{array}{l}\text { 8. Participação } \\
\text { conjunta em feiras, etc }\end{array}$} & 13 & 6 & 6 & 14 & 0,43 & 0 & 0 & 0 & 1 & 1 & 0 & 0 & 0 & 1 & 1 \\
\hline & $33,30 \%$ & $15,40 \%$ & $15,40 \%$ & $35,90 \%$ & & $0,00 \%$ & $0,00 \%$ & $0,00 \%$ & $100,00 \%$ & & $0,00 \%$ & $0,00 \%$ & $0,00 \%$ & $100,00 \%$ & \\
\hline \multirow[t]{2}{*}{ 9. Outras } & 19 & 0 & 0 & 5 & 0,11 & 1 & 0 & 0 & 0 & 0 & 0 & 0 & 0 & 1 & 1 \\
\hline & $79,20 \%$ & $0,00 \%$ & $0,00 \%$ & $20,80 \%$ & & $100,00 \%$ & $0,00 \%$ & $0,00 \%$ & $0,00 \%$ & & $0,00 \%$ & $0,00 \%$ & $0,00 \%$ & $100,00 \%$ & \\
\hline
\end{tabular}

Fonte: pesquisa de campo.

${ }^{*}$ Índice $=\left(0^{*} \mathrm{~N}^{\circ}\right.$ nulas $+0,3 * \mathrm{~N}^{\circ}$ baixas $+0,6 * \mathrm{~N}^{\circ}$ médias $+\mathrm{N}^{\circ}$ altas $) /\left(\mathrm{N}^{\circ}\right.$ total de empresas $)$. 
Para as pequenas e médias empresas, outros aspectos da cooperação são assinalados como importantes. Assim, é ressaltada a cooperação no auxílio à capacitação dos recursos humanos e na melhor definição do estilo e design dos produtos.

Tabela 20: Avaliação das ações conjuntas.

\begin{tabular}{|c|c|c|c|c|c|c|c|}
\hline \multirow{2}{*}{ Descrição } & \multicolumn{5}{|c|}{ Micro } & \multirow{2}{*}{$\begin{array}{c}\text { Peq. } \\
\text { Índice* }\end{array}$} & \multirow{2}{*}{$\begin{array}{l}\text { Méd. } \\
\text { Indice }\end{array}$} \\
\hline & Nula & Baixa & Média & Alta & Índice ${ }^{*}$ & & \\
\hline $\begin{array}{l}\text { 1. Melhoria na qualidade } \\
\text { dos produtos }\end{array}$ & $\begin{array}{c}13 \\
36,10 \%\end{array}$ & $\begin{array}{c}5 \\
13,90 \%\end{array}$ & $\begin{array}{c}9 \\
25,00 \%\end{array}$ & $\begin{array}{c}9 \\
25,00 \%\end{array}$ & 0,35 & 0,6 & 0,6 \\
\hline $\begin{array}{l}\text { 2. Desenvolvimento de } \\
\text { novos produtos }\end{array}$ & $\begin{array}{c}10 \\
27,80 \% \\
\end{array}$ & $\begin{array}{c}4 \\
11,10 \% \\
\end{array}$ & $\begin{array}{c}8 \\
22,20 \% \\
\end{array}$ & $\begin{array}{c}14 \\
38,90 \% \\
\end{array}$ & 0,44 & 0,6 & 0,6 \\
\hline $\begin{array}{l}\text { 3. Melhoria nos processos } \\
\text { produtivos }\end{array}$ & $\begin{array}{c}14 \\
38,90 \% \\
\end{array}$ & $\begin{array}{c}9 \\
25,00 \% \\
\end{array}$ & $\begin{array}{c}5 \\
13,90 \% \\
\end{array}$ & $\begin{array}{c}8 \\
22,20 \% \\
\end{array}$ & 0,3 & 0,3 & 0 \\
\hline $\begin{array}{l}\text { 4. Melhoria nas condições } \\
\text { de fornecimento dos } \\
\text { produtos }\end{array}$ & $\begin{array}{c}17 \\
47,20 \%\end{array}$ & $\begin{array}{c}6 \\
16,70 \% \\
\end{array}$ & $\begin{array}{c}5 \\
13,90 \% \\
\end{array}$ & $\begin{array}{c}8 \\
22,20 \% \\
\end{array}$ & 0,28 & 0 & 0,6 \\
\hline $\begin{array}{l}\text { 5. Melhor capacitação de } \\
\text { recursos humanos }\end{array}$ & $\begin{array}{c}15 \\
41,70 \% \\
\end{array}$ & $\begin{array}{c}10 \\
27,80 \% \\
\end{array}$ & $\begin{array}{c}6 \\
16,70 \% \\
\end{array}$ & $\begin{array}{c}5 \\
13,90 \% \\
\end{array}$ & 0,26 & 0,6 & 1 \\
\hline $\begin{array}{l}\text { 6. Melhoria nas condições } \\
\text { de comercialização }\end{array}$ & $\begin{array}{c}10 \\
27,80 \% \\
\end{array}$ & $\begin{array}{c}0 \\
0,00 \% \\
\end{array}$ & $\begin{array}{c}12 \\
33,30 \% \\
\end{array}$ & $\begin{array}{c}14 \\
38,90 \% \\
\end{array}$ & 0,47 & 0,3 & 1 \\
\hline $\begin{array}{l}\text { 7. Introdução de inovações } \\
\text { organizacionais }\end{array}$ & $\begin{array}{c}18 \\
50,00 \% \\
\end{array}$ & $\begin{array}{c}5 \\
13,90 \% \\
\end{array}$ & $\begin{array}{c}9 \\
25,00 \% \\
\end{array}$ & $\begin{array}{c}4 \\
11,10 \% \\
\end{array}$ & 0,24 & 0,6 & 1 \\
\hline $\begin{array}{l}\text { 8. Novas oportunidades de } \\
\text { negócios }\end{array}$ & $\begin{array}{c}10 \\
27,80 \% \\
\end{array}$ & $\begin{array}{c}1 \\
2,80 \% \\
\end{array}$ & $\begin{array}{c}3 \\
8,30 \% \\
\end{array}$ & $\begin{array}{c}22 \\
61,10 \% \\
\end{array}$ & 0,54 & 0 & 1 \\
\hline $\begin{array}{l}\text { 9. Promoção de } \\
\text { nome/marca da empresa } \\
\text { no mercado nacional }\end{array}$ & $\begin{array}{c}13 \\
36,10 \% \\
\end{array}$ & $\begin{array}{c}4 \\
11,10 \% \\
\end{array}$ & $\begin{array}{c}7 \\
19,40 \% \\
\end{array}$ & $\begin{array}{c}12 \\
33,30 \% \\
\end{array}$ & 0,39 & 0,6 & 1 \\
\hline $\begin{array}{l}\text { 10. Maior inserção da } \\
\text { empresa no mercado } \\
\text { externo }\end{array}$ & $\begin{array}{c}19 \\
52,80 \% \\
\end{array}$ & $\begin{array}{c}2 \\
5,60 \% \\
\end{array}$ & $\begin{array}{c}5 \\
13,90 \% \\
\end{array}$ & $\begin{array}{c}10 \\
27,80 \% \\
\end{array}$ & 0,3 & 0,6 & 1 \\
\hline 11. Outras & $\begin{array}{c}25 \\
100,00 \% \\
\end{array}$ & $\begin{array}{c}0 \\
0,00 \% \\
\end{array}$ & $\begin{array}{c}0 \\
0,00 \% \\
\end{array}$ & $\begin{array}{c}0 \\
0,00 \% \\
\end{array}$ & 0 & 0 & 0 \\
\hline
\end{tabular}

Fonte: pesquisa de campo.

*Índice $=\left(0^{*} \mathrm{~N}^{\circ}\right.$ nulas $+0,3 * \mathrm{~N}^{\circ}$ baixas $+0,6 * \mathrm{~N}^{\circ}$ médias $+\mathrm{N}^{\circ}$ altas $) /\left(\mathrm{N}^{\mathrm{o}}\right.$ total de empresas).

Para aqueles artesãos vinculados a algum tipo de associativismo, a ação conjunta de maior alcance é justamente aquela que permite a melhoria das condições de comercialização e a abertura de novas oportunidades de negócios, o que inclui empresas de diferentes portes. 
Tabela 21: Resultado dos processos de treinamento e aprendizagem.

\begin{tabular}{|c|c|c|c|c|c|c|c|}
\hline \multirow[b]{2}{*}{ Descrição } & \multicolumn{5}{|c|}{ Micro } & \multirow{2}{*}{\begin{tabular}{|c|} 
Peq. \\
Índice* $^{*}$
\end{tabular}} & \multirow{2}{*}{$\begin{array}{c}\text { Méd. } \\
\text { Indice* }\end{array}$} \\
\hline & Nula & Baixa & Média & Alta & Índice* & & \\
\hline $\begin{array}{l}\text { 1. Melhor utilização de técnicas } \\
\text { produtivas, equipamentos, insumos } \\
\text { e componentes }\end{array}$ & $\begin{array}{c}5 \\
15,20 \%\end{array}$ & $\begin{array}{c}1 \\
3,00 \%\end{array}$ & $\begin{array}{c}11 \\
33,30 \%\end{array}$ & $\begin{array}{c}16 \\
48,50 \%\end{array}$ & 0,69 & 1 & 1 \\
\hline $\begin{array}{l}\text { 2. Maior capacitação para realização } \\
\text { de modificaçōes e melhorias em } \\
\text { produtos e processos }\end{array}$ & $\begin{array}{c}5 \\
15,20 \%\end{array}$ & $\begin{array}{c}9 \\
27,30 \%\end{array}$ & $\begin{array}{c}7 \\
21,20 \%\end{array}$ & $\begin{array}{c}12 \\
36,40 \%\end{array}$ & 0,57 & 1 & 1 \\
\hline $\begin{array}{l}\text { 3. Melhor capacitação para } \\
\text { desenvolver novos produtos e } \\
\text { processos }\end{array}$ & $\begin{array}{c}6 \\
18,80 \%\end{array}$ & $\begin{array}{c}3 \\
9,40 \%\end{array}$ & $\begin{array}{c}11 \\
34,40 \%\end{array}$ & $\begin{array}{c}12 \\
37,50 \%\end{array}$ & 0,61 & 1 & 1 \\
\hline $\begin{array}{l}\text { 4. Maior conhecimento sobre as } \\
\text { características dos mercados de } \\
\text { atuação da empresa }\end{array}$ & $\begin{array}{c}9 \\
27,30 \%\end{array}$ & $\begin{array}{c}1 \\
3,00 \%\end{array}$ & $\begin{array}{c}7 \\
21,20 \%\end{array}$ & $\begin{array}{c}16 \\
48,50 \% \\
\end{array}$ & 0,62 & 1 & 1 \\
\hline 5. Melhor capacitação administra & 10 & 3 & 12 & 8 & 0,49 & 0,3 & \\
\hline
\end{tabular}

Fonte: pesquisa de campo.

Quanto ao processo de treinamento e aprendizado, a avaliação dos artesãos difere conforme os segmentos recebem ou não a influência do poder público. Entretanto, o conjunto dos resultados mostra uma avaliação positiva quanto aos diferentes itens abordados, como melhor utilização de técnicas produtivas, equipamentos, insumos e componentes, maior capacitação para realização de modificações e melhorias em produtos e processos, melhor capacitação para desenvolver novos produtos e processos, maior conhecimento sobre as características dos mercados de atuação da empresa e melhor capacitação administrativa. As respostas mostram a importância relativa de cada item avaliado.

Segundo os resultados apresentados na Tabela 23, as principais transações comerciais realizadas pelas unidades econômicas no arranjo são a aquisição das matérias-primas e a venda dos produtos. Isso serve de referência para as vantagens apontadas (Tabela 22) por essas mesmas unidades por se localizarem no arranjo. Desse modo, os maiores índices estão exatamente relacionados aos itens supracitados, quanto à proximidade de fornecedores de insumos e matérias-primas, bem como com clientes e consumidores. A infra-estrutura física e a disponibilidade de mão-de-obra qualificada também são apontadas como de grande relevância, especialmente por aquelas unidades que estão em espaços físicos coordenados pelo Estado. 
Tabela 22: Vantagem da localização no arranjo.

\begin{tabular}{|c|c|c|c|c|c|c|c|c|c|c|c|c|c|c|c|}
\hline \multirow{2}{*}{ Externalidades } & \multicolumn{5}{|c|}{ Micro } & \multicolumn{5}{|c|}{ Pequena } & \multicolumn{5}{|c|}{ Média } \\
\hline & Nula & Baixa & Média & Alta & Índice* & Nula & Baixa & Média & Alta & Índice* & Nula & Baixa & Média & Alta & Índice $^{*}$ \\
\hline \multirow{2}{*}{$\begin{array}{l}\text { 1. Disponibilidade de mão- } \\
\text { de-obra qualificada }\end{array}$} & 13 & 4 & 8 & 20 & 0,58 & 0 & 1 & 0 & 0 & 0,3 & 0 & 0 & 1 & 0 & 0,6 \\
\hline & $28,9 \%$ & $8,9 \%$ & $17,8 \%$ & $44,4 \%$ & & $0,0 \%$ & $100,0 \%$ & $0,0 \%$ & $0,0 \%$ & & $0,0 \%$ & $0,0 \%$ & $100,0 \%$ & $0,0 \%$ & \\
\hline \multirow{2}{*}{$\begin{array}{l}\text { 2. Baixo custo da mão-de- } \\
\text { obra }\end{array}$} & 15 & 6 & 21 & 3 & 0,39 & 0 & 1 & 0 & 0 & 0,3 & 0 & 0 & 1 & 0 & 0,6 \\
\hline & $33,3 \%$ & $13,3 \%$ & $46,7 \%$ & $6,7 \%$ & & $0,0 \%$ & $100,0 \%$ & $0,0 \%$ & $0,0 \%$ & & $0,0 \%$ & $0,0 \%$ & $100,0 \%$ & $0,0 \%$ & \\
\hline \multirow{2}{*}{$\begin{array}{l}\text { 3. Proximidade dos } \\
\text { fornecedores de insumos e } \\
\text { matéria-prima }\end{array}$} & 0 & 7 & 4 & 34 & 0,86 & 0 & 1 & 0 & 0 & 0,3 & 0 & 0 & 0 & 1 & 1 \\
\hline & $0,0 \%$ & $15,6 \%$ & $8,9 \%$ & $75,6 \%$ & & $0,0 \%$ & $100,0 \%$ & $0,0 \%$ & $0,0 \%$ & & $0,0 \%$ & $0,0 \%$ & $0,0 \%$ & $100,0 \%$ & \\
\hline \multirow{2}{*}{$\begin{array}{l}\text { 4. Proximidade dos } \\
\text { clientes/consumidores }\end{array}$} & 2 & 3 & 9 & 30 & 0,83 & 0 & 0 & 1 & 0 & 0,6 & 0 & 0 & 0 & 1 & 1 \\
\hline & $4,5 \%$ & $6,8 \%$ & $20,5 \%$ & $68,2 \%$ & & $0,0 \%$ & $0,0 \%$ & $100,0 \%$ & $0,0 \%$ & & $0,0 \%$ & $0,0 \%$ & $0,0 \%$ & $100,0 \%$ & \\
\hline \multirow{2}{*}{$\begin{array}{l}\text { 5. Infra-estrutura física } \\
\text { (energia, transporte, } \\
\text { comunicações) }\end{array}$} & 7 & 6 & 14 & 18 & 0,63 & 0 & 0 & 1 & 0 & 0,6 & 0 & 0 & 1 & 0 & 0,6 \\
\hline & $15,6 \%$ & $13,3 \%$ & $31,1 \%$ & $40,0 \%$ & & $0,0 \%$ & $0,0 \%$ & $100,0 \%$ & $0,0 \%$ & & $0,0 \%$ & $0,0 \%$ & $100,0 \%$ & $0,0 \%$ & \\
\hline \multirow{2}{*}{$\begin{array}{l}\text {. Proximidade dos } \\
\text { produtores de } \\
\text { equipamentos }\end{array}$} & 30 & 6 & 2 & 7 & 0,22 & 0 & 1 & 0 & 0 & 0,3 & 1 & 0 & 0 & 0 & 0 \\
\hline & $66,7 \%$ & $13,3 \%$ & $4,4 \%$ & $15,6 \%$ & & $0,0 \%$ & $100,0 \%$ & $0,0 \%$ & $0,0 \%$ & & $100,0 \%$ & $0,0 \%$ & $0,0 \%$ & $0,0 \%$ & \\
\hline \multirow{2}{*}{$\begin{array}{l}\text { 7. Disponibilidade de } \\
\text { serviços técnicos } \\
\text { especializados }\end{array}$} & 29 & 6 & 1 & 8 & 0,24 & 0 & 0 & 1 & 0 & 0,6 & 1 & 0 & 0 & 0 & 0 \\
\hline & $65,9 \%$ & $13,6 \%$ & $2,3 \%$ & $18,2 \%$ & & $0,0 \%$ & $0,0 \%$ & $100,0 \%$ & $0,0 \%$ & & $100,0 \%$ & $0,0 \%$ & $0,0 \%$ & $0,0 \%$ & \\
\hline \multirow[t]{2}{*}{$\begin{array}{l}\text { 8. Existência de programas } \\
\text { de apoio e promoçâo }\end{array}$} & 22 & 5 & 5 & 13 & 0,39 & 0 & 0 & 1 & 0 & 0,6 & 0 & 0 & 0 & 1 & 1 \\
\hline & $48,9 \%$ & $11,1 \%$ & $11,1 \%$ & $28,9 \%$ & & $0,0 \%$ & $0,0 \%$ & $100,0 \%$ & $0,0 \%$ & & $0,0 \%$ & $0,0 \%$ & $0,0 \%$ & $100,0 \%$ & \\
\hline \multirow{2}{*}{$\begin{array}{l}\text { 9. Proximidade de } \\
\text { universidades e centros de } \\
\text { pesquisa }\end{array}$} & 29 & 7 & 2 & 7 & 0,23 & 0 & 0 & 1 & 0 & 0,6 & 0 & 0 & 1 & 0 & 0,6 \\
\hline & $64,4 \%$ & $15,6 \%$ & $4,4 \%$ & $15,6 \%$ & & $0,0 \%$ & $0,0 \%$ & $100,0 \%$ & $0,0 \%$ & & $0,0 \%$ & $0,0 \%$ & $100,0 \%$ & $0,0 \%$ & \\
\hline \multirow[t]{2}{*}{ 10. Outra } & 39 & 0 & 2 & 0 & 0,03 & 1 & 0 & 0 & 0 & 0 & 1 & 0 & 0 & 0 & 0 \\
\hline & $95,1 \%$ & $0,0 \%$ & $4,9 \%$ & $0,0 \%$ & & $100,0 \%$ & $0,0 \%$ & $0,0 \%$ & $0,0 \%$ & & $100,0 \%$ & $0,0 \%$ & $0,0 \%$ & $0,0 \%$ & \\
\hline
\end{tabular}

Fonte: pesquisa de campo.

${ }^{*}$ Índice $=\left(0^{*} \mathrm{~N}^{\circ}\right.$ nulas $+0,3{ }^{*} \mathrm{~N}^{\circ}$ baixas $+0,6{ }^{*} \mathrm{~N}^{\circ}$ médias $+\mathrm{N}^{\mathrm{O}}$ altas $) /\left(\mathrm{N}^{\mathrm{O}}\right.$ empresas no segmento $)$. 
Tabela 23: Principais transações comerciais realizadas no arranjo para às micro e pequenas empresas.

\begin{tabular}{|c|c|c|c|c|c|c|c|c|c|c|}
\hline \multirow{2}{*}{ Tipos de transações } & \multicolumn{5}{|c|}{ Micro } & \multicolumn{5}{|c|}{ Pequena } \\
\hline & Nula & Baixa & Média & Alta & Índice* & Nula & Baixa & Média & Alta & Índice* \\
\hline \multirow[t]{2}{*}{$\begin{array}{l}\text { 1. Aquísição de insumos } \\
\text { e matéria-prima }\end{array}$} & 2 & 1 & 6 & 36 & 0,89 & 0 & 1 & 0 & 0 & 0,3 \\
\hline & $4,4 \%$ & $2,2 \%$ & $13,3 \%$ & $80,0 \%$ & & $0,0 \%$ & $100,0 \%$ & $0,0 \%$ & $0,0 \%$ & \\
\hline \multirow{2}{*}{$\begin{array}{l}\text { 2. Aquisição de } \\
\text { equipamentos }\end{array}$} & 24 & 9 & 9 & 3 & 0,25 & 0 & 1 & 0 & 0 & 0,3 \\
\hline & $53,3 \%$ & $20,0 \%$ & $20,0 \%$ & $6,7 \%$ & & $0,0 \%$ & $100,0 \%$ & $0,0 \%$ & $0,0 \%$ & \\
\hline \multirow{2}{*}{$\begin{array}{l}\text { 3. Aquisição de } \\
\text { componentes e peças }\end{array}$} & 16 & 5 & 2 & 0 & 0.12 & 0 & 1 & 0 & 0 & 0,3 \\
\hline & $69,6 \%$ & $21,7 \%$ & $8,7 \%$ & $0,0 \%$ & & $0,0 \%$ & $100,0 \%$ & $0,0 \%$ & $0,0 \%$ & \\
\hline \multirow{2}{*}{$\begin{array}{l}\text { 4. Aquisição de serviços } \\
\text { (manutenção, } \\
\text { marketing, etc.) }\end{array}$} & 30 & 7 & 6 & 1 & 0,15 & 0 & 0 & 1 & 0 & 0,6 \\
\hline & $68,2 \%$ & $15,9 \%$ & $13,6 \%$ & $2,3 \%$ & & $0,0 \%$ & $0,0 \%$ & $100,0 \%$ & $0,0 \%$ & \\
\hline \multirow[t]{2}{*}{ 5. Vendas de produtos } & 0 & 1 & 6 & 38 & 0,93 & 0 & 0 & 1 & 0 & 0,6 \\
\hline & $0,0 \%$ & $2,2 \%$ & $13,3 \%$ & $84,4 \%$ & & $0,0 \%$ & $0,0 \%$ & $100,0 \%$ & $0,0 \%$ & \\
\hline
\end{tabular}

Fonte: pesquisa de campo.

*Índice $=\left(0^{*} \mathrm{~N}^{\circ}\right.$ nulas $+0,3 * \mathrm{~N}^{\circ}$ baixas $+0,6 * \mathrm{~N}^{\circ}$ médias $+\mathrm{N}^{\circ}$ altas $) /\left(\mathrm{N}^{\circ}\right.$ empresas no segmento).

Como era esperado, a escolaridade formal em seus diferentes níveis não é apontada como característica expressiva para o desenvolvimento da atividade, pelo menos para as microempresas. Maior importância é atribuída ao conhecimento prático e/ou técnico que não tem natureza formal e à criatividade, à disciplina e à capacidade para apreender novas qualificações. Isso é demonstrado pelos resultados apresentados na Tabela 24.

Tabela 24: Avaliação da contribuição de sindicatos, associações e cooperativas locais.

\begin{tabular}{l|c|c|c}
\hline \multicolumn{1}{c|}{ Tipo de contribuição } & $\begin{array}{c}\text { Micro } \\
\text { Índice* }\end{array}$ & $\begin{array}{c}\text { Peq } \\
\text { Índice* }\end{array}$ & $\begin{array}{c}\text { Méd } \\
\text { Índice }\end{array}$ \\
\hline $\begin{array}{l}\text { 1. Auxílio na definição de objetivos comuns para o } \\
\text { arranjo produtivo }\end{array}$ & 0,37 & 0,60 & 1,00 \\
$\begin{array}{l}\text { 2. Estímulo na percepção de visões de futuro para ação } \\
\text { estratégica }\end{array}$ & 0,38 & 0,60 & 1,00 \\
3. Disponibilização de informações sobre matérias-primas, & & & \\
equipamento, assistência técnica, consultoria, etc. & 0,36 & 0,60 & 1,00 \\
4. Identificação de fontes e formas de financiamento & 0,58 & 0,60 & 1,00 \\
5. Promoção de ações cooperativas & 0,37 & 0,60 & 1,00 \\
6. Apresentação de reivindicações comuns & 0,40 & 0,60 & 1,00 \\
7. Criação de fóruns e ambientes para discussão & 0,32 & 0,30 & 1,00 \\
$\begin{array}{l}\text { 8. Promoção de ações dirigidas à capacitação tecnológica } \\
\text { de empresas }\end{array}$ & 0,31 & 0,60 & 0,00 \\
9. Estímulo ao desenvolvimento do sistema de ensino e & & & \\
pesquisa local & 0,30 & 0,60 & 1,00 \\
10. Organização de eventos técnicos e comerciais & 0,47 & 0,60 & 1,00 \\
\hline
\end{tabular}

Fonte: pesquisa de campo.

*Índice $=\left(0^{*} \mathrm{~N}^{\circ}\right.$ nulas $+0,3 * \mathrm{~N}^{\circ}$ baixas $+0,6 * \mathrm{~N}^{\circ}$ médias $+\mathrm{N}^{\circ}$ altas $) /\left(\mathrm{N}^{\circ}\right.$ empresas no segmento).

Por outro lado, como a grande maioria dos artesãos não é 
sindicalizada ${ }^{3}$, a avaliação incide na participação das associações ou nas formas de cooperativismo não necessariamente formais existentes. De certo, há uma certa desconfiança quanto ao papel de liderança dessas entidades representativas. Por isso, somente os itens "identificação de fontes de financiamento" e "organização de eventos técnicos e comerciais" são apontados como contribuição efetiva das formas de associativismo.

A participação em programas governamentais restringe-se praticamente àqueles implantados pelo governo estadual e pelo governo municipal, como assinalado pelas microempresas (ver Tabela 25). Também é destacada a participação efetiva do SEBRAE. Em todos os casos, a avaliação foi considerada positiva.

As pequenas empresas dizem participar de programas em todas as esferas de governo e com outras instituições, inclusive o SEBRAE, com exceção dos programas no âmbito federal, embora os conheçam. As médias informam participar de programas apenas com o SEBRAE.

Tabela 25: Participação das microempresas em programas públicos ou ações no segmento onde atua.

\begin{tabular}{l|cccc}
\hline \multirow{2}{*}{ Instituição } & \multicolumn{3}{c}{ Micro } \\
\cline { 2 - 4 } & Não conhece & $\begin{array}{c}\text { Conhece, mas } \\
\text { não participa }\end{array}$ & $\begin{array}{c}\text { Conhece e } \\
\text { participa }\end{array}$ \\
\hline 1. Governo federal & 35 & 6 & 4 \\
2. Governo estadual & $77,80 \%$ & $13,30 \%$ & $8,90 \%$ \\
& 29 & 8 & 8 \\
3. Governo local/municipal & $64,40 \%$ & $17,80 \%$ & $17,80 \%$ \\
4. SEBRAE & 19 & 17 & 9 \\
& $42,20 \%$ & $37,80 \%$ & $20,60 \%$ \\
5. Outras instituições & 15 & 12 & 18 \\
& $33,30 \%$ & $26,70 \%$ & $40,10 \%$ \\
& 21 & 0 & 1 \\
\hline
\end{tabular}

Fonte: pesquisa de campo.

Tabela 26: Avaliação dos programas governamentais.

\begin{tabular}{l|ccc|c|c|c}
\hline \multirow{2}{*}{ In stituição } & \multicolumn{3}{|c|}{ Micro } & \multicolumn{3}{c}{ Pequena } \\
\cline { 2 - 7 } & $\begin{array}{c}\text { Avaliação } \\
\text { positiva }\end{array}$ & $\begin{array}{c}\text { Avaliação } \\
\text { negativa }\end{array}$ & $\begin{array}{c}\text { Sem elementos } \\
\text { para avaliação }\end{array}$ & $\begin{array}{c}\text { Avaliação } \\
\text { positiva }\end{array}$ & $\begin{array}{c}\text { Avaliação } \\
\text { negativa }\end{array}$ & $\begin{array}{c}\text { Sem elementos } \\
\text { para avaliação }\end{array}$ \\
\hline 1. Governo & 3 & 5 & 32 & 0 & 0 & 1 \\
federal & $7,50 \%$ & $12,50 \%$ & $80,00 \%$ & $0,00 \%$ & $0,00 \%$ & $100,00 \%$ \\
2. Governo & 9 & 3 & 27 & 1 & 0 & 0 \\
estadual & $23,10 \%$ & $7,70 \%$ & $69,20 \%$ & $100,00 \%$ & $0,00 \%$ & $0,00 \%$ \\
3. Goevrno & 15 & 3 & 22 & 1 & 0 & 0 \\
local/municipal & $37,50 \%$ & $7,50 \%$ & $55,00 \%$ & $100,00 \%$ & $0,00 \%$ & $0,00 \%$ \\
4. SEBRAE & 18 & 6 & 16 & 1 & 0 & 0 \\
& $45,00 \%$ & $15,00 \%$ & $40,00 \%$ & $100,00 \%$ & $0,00 \%$ & $0,00 \%$ \\
5. Outras & 1 & 1 & 38 & 1 & 0 & 0 \\
instituições & $2,50 \%$ & $2,50 \%$ & $95,00 \%$ & $100,00 \%$ & $0,00 \%$ & $0,00 \%$ \\
\hline
\end{tabular}

Fonte: pesquisa de campo.

\footnotetext{
${ }^{3}$ Foi identificado um único sindicato da categoria: o Sindicato dos Artesãos Autônomos de Belém (SINAAB)
} 
Tabela 27: Políticas públicas que poderiam ajudar a atividade.

\begin{tabular}{|c|c|c|c|c|c|c|c|c|c|c|c|c|c|c|c|}
\hline \multirow{2}{*}{ Ações de política } & \multicolumn{5}{|c|}{ Micro } & \multicolumn{5}{|c|}{ Pequena } & \multicolumn{5}{|c|}{ Média } \\
\hline & Nula & Baixa & Média & Alta & Índice* & Nula & Baixa & Média & Alta & Índice* & Nula & Baixa & Média & Alta & Índice* \\
\hline \multirow{2}{*}{$\begin{array}{l}\text { 1. Programas de capacitação profissional e } \\
\text { treinamento técnico }\end{array}$} & 7 & 4 & 6 & 28 & 0,73 & 0 & 0 & 0 & 1 & 1 & 0 & 0 & 0 & 1 & 1 \\
\hline & $15,6 \%$ & $8,9 \%$ & $13,3 \%$ & $62,2 \%$ & & $0,0 \%$ & $0,0 \%$ & $0,0 \%$ & $100,0 \%$ & & $0,0 \%$ & $0,0 \%$ & $0,0 \%$ & $100,0 \%$ & \\
\hline \multirow[t]{2}{*}{ 2. Melhorias na educação básica } & 7 & 5 & 6 & 26 & 0,71 & 0 & 0 & 1 & 0 & 0,6 & 0 & 0 & 0 & 1 & 1 \\
\hline & $15,9 \%$ & $11,4 \%$ & $13,6 \%$ & $59,1 \%$ & & $0,0 \%$ & $0,0 \%$ & $100,0 \%$ & $0,0 \%$ & & $0,0 \%$ & $0,0 \%$ & $0,0 \%$ & $100,0 \%$ & \\
\hline \multirow{2}{*}{$\begin{array}{l}\text { 3. Programas de apoio à consultoria } \\
\text { técnica }\end{array}$} & 16 & 8 & 4 & 17 & 0,48 & 0 & 0 & 0 & 1 & 1 & 0 & 0 & 0 & 1 & 1 \\
\hline & $35,6 \%$ & $17,8 \%$ & $8,9 \%$ & $37,8 \%$ & & $0,0 \%$ & $0,0 \%$ & $0,0 \%$ & $100,0 \%$ & & $0,0 \%$ & $0,0 \%$ & $0,0 \%$ & $100,0 \%$ & \\
\hline \multirow{2}{*}{$\begin{array}{l}\text { 4. Estímulos à oferta de serviços } \\
\text { tecnológicos }\end{array}$} & 25 & 4 & 2 & 14 & 0,36 & 0 & 0 & 1 & 0 & 0,6 & 0 & 0 & 0 & 1 & 1 \\
\hline & $55,6 \%$ & $8,9 \%$ & $4,4 \%$ & $31,1 \%$ & & $0,0 \%$ & $0,0 \%$ & $100,0 \%$ & $0,0 \%$ & & $0,0 \%$ & $0,0 \%$ & $0,0 \%$ & $100,0 \%$ & \\
\hline \multirow{2}{*}{$\begin{array}{l}\text { 5. Programas de acesso à informação } \\
\text { (produção, tecnologia, mercados, etc.) }\end{array}$} & 18 & 4 & 7 & 15 & 0,46 & 0 & 0 & 0 & 1 & 1 & 0 & 0 & 0 & 1 & 1 \\
\hline & $40,9 \%$ & $9,1 \%$ & $15,9 \%$ & $34,1 \%$ & & $0,0 \%$ & $0,0 \%$ & $0,0 \%$ & $100,0 \%$ & & $0,0 \%$ & $0,0 \%$ & $0,0 \%$ & $100,0 \%$ & \\
\hline \multirow{2}{*}{$\begin{array}{l}\text { 6. Linhas de crédito e outras formas de } \\
\text { financiamento }\end{array}$} & 4 & 3 & 3 & 34 & 0,83 & 0 & 0 & 1 & 0 & 0,6 & 0 & 0 & 0 & 1 & 1 \\
\hline & $9,1 \%$ & $6,8 \%$ & $6,8 \%$ & $77,3 \%$ & & $0,0 \%$ & $0,0 \%$ & $100,0 \%$ & $0,0 \%$ & & $0,0 \%$ & $0,0 \%$ & $0,0 \%$ & $100,0 \%$ & \\
\hline \multirow[t]{2}{*}{ 7. Incentivos fiscais } & 21 & 6 & 6 & 12 & 0,39 & 1 & 0 & 0 & 0 & 0 & 0 & 0 & 0 & 1 & 1 \\
\hline & $46,7 \%$ & $13,3 \%$ & $13,3 \%$ & $26,7 \%$ & & $100,0 \%$ & $0,0 \%$ & $0,0 \%$ & $0,0 \%$ & & $0,0 \%$ & $0,0 \%$ & $0,0 \%$ & $100,0 \%$ & \\
\hline \multirow[t]{2}{*}{ 8. Políticas de fundo de aval } & 24 & 4 & 1 & 16 & 0,4 & 0 & 0 & 1 & 0 & 0,6 & 0 & 0 & 0 & 1 & 1 \\
\hline & $53,3 \%$ & $8,9 \%$ & $2,2 \%$ & $35,6 \%$ & & $0,0 \%$ & $0,0 \%$ & $100,0 \%$ & $0,0 \%$ & & $0,0 \%$ & $0,0 \%$ & $0,0 \%$ & $100,0 \%$ & \\
\hline \multirow{2}{*}{$\begin{array}{l}\text { 9. Programas de estímulo ao investimento } \\
\text { (venture capital) }\end{array}$} & 35 & 2 & 2 & 5 & 0,15 & 0 & 1 & 0 & 0 & 0,3 & 0 & 0 & 0 & 1 & 1 \\
\hline & $79,5 \%$ & $4,5 \%$ & $4,5 \%$ & $11,4 \%$ & & $0,0 \%$ & $100,0 \%$ & $0,0 \%$ & $0,0 \%$ & & $0,0 \%$ & $0,0 \%$ & $0,0 \%$ & $100,0 \%$ & \\
\hline \multirow[t]{2}{*}{ 10. Outras } & 30 & 1 & 0 & 9 & 0,23 & 1 & 0 & 0 & 0 & $\overline{0}$ & 0 & 0 & 0 & 0 & 0 \\
\hline & $75,0 \%$ & $2,5 \%$ & $0,0 \%$ & $22,5 \%$ & & $100,0 \%$ & $0,0 \%$ & $0,0 \%$ & $0,0 \%$ & & $0,0 \%$ & $0,0 \%$ & $0,0 \%$ & $0,0 \%$ & \\
\hline
\end{tabular}

Fonte: pesquisa de campo.

岂 $\quad *$ Índice $=\left(0^{*} \mathrm{~N}^{\circ}\right.$ nulas $+0,3 * \mathrm{~N}^{\circ}$ baixas $+0,6{ }^{*} \mathrm{~N}^{\circ}$ médias $+\mathrm{N}^{\circ}$ altas $) /\left(\mathrm{N}^{\circ}\right.$ empresas no segmento $)$. 
A avaliação pelos entrevistados das políticas públicas que poderiam ajudar a atividade confirma as análises anteriores. Assim, é destacada a importância da capacitação e da melhoria da educação básica, juntamente com o acesso a linhas de crédito e outras formas de financiamento. Aliás, quanto às linhas de crédito, como evidenciam os resultados da Tabela 33, fica bem claro que elas atualmente não atendem as necessidades dos produtores, seja pelos entraves burocráticos, seja pelas exigências de garantia e aval, o que muitas vezes torna inacessível o crédito. As experiências com crédito têm-se limitado, na maioria dos casos, aos recursos mobilizados no Banco do Povo, para socorrer "necessidades mais imediatas" de capital de giro ou cobrir algum prejuízo. Isso pode ser, sem dúvida, um fator limitante da expansão da atividade, em termos tanto quantitativos como qualitativos. Assim, por exemplo, no segmento de fabricação de jóias, os produtores afirmam que seus equipamentos estão obsoletos tecnologicamente e, ao mesmo tempo, declaram que as necessidades de capital de giro são altas; sem as possibilidades de empréstimos, fica limitada sua capacidade de atender grandes encomendas.

A necessidade de maior segurança pública é particularmente destacada pelos "artesãos de rua", pelos que vivem da exposição de seus produtos em feiras e mercados. Isso também é bastante enfatizado pelos artesãos de Icoaraci; para eles, a falta de segurança pública impede que um número maior de turistas procure o local. Esses artesãos queixam-se ainda da falta de uma maior infra-estrutura turística no bairro do Pacuri, que seria indispensável para incrementar o turismo. 
Tabela 28: Obstáculos a obtenção de crédito.

\begin{tabular}{|c|c|c|c|c|c|c|c|c|c|c|c|c|c|c|c|}
\hline \multirow{2}{*}{ Limitações } & \multicolumn{5}{|c|}{ Micro } & \multicolumn{5}{|c|}{ Pequena } & \multicolumn{5}{|c|}{ Média } \\
\hline & Nula & Baixa & Média & Alta & Índice ${ }^{*}$ & Nula & Baixa & Média & Alta & Índice* & Nula & Baixa & Média & Alta & Índice $^{*}$ \\
\hline $\begin{array}{l}\text { 1. Inexistência de linhas de crédito } \\
\text { adequadas às necessidades da } \\
\text { empresa }\end{array}$ & $\begin{array}{c}7 \\
15,9 \% \\
\end{array}$ & $\begin{array}{c}0 \\
0,0 \% \\
\end{array}$ & $\begin{array}{c}6 \\
13,6 \% \\
\end{array}$ & $\begin{array}{c}31 \\
70,5 \% \\
\end{array}$ & 0,79 & $\begin{array}{c}0 \\
0,0 \% \\
\end{array}$ & $\begin{array}{c}0 \\
0,0 \% \\
\end{array}$ & $\begin{array}{c}1 \\
100,0 \% \\
\end{array}$ & $\begin{array}{c}0 \\
0,0 \% \\
\end{array}$ & 0,6 & $\begin{array}{c}0 \\
0,0 \% \\
\end{array}$ & $\begin{array}{c}0 \\
0,0 \% \\
\end{array}$ & $\begin{array}{c}0 \\
0,0 \% \\
\end{array}$ & $\begin{array}{c}1 \\
100,0 \% \\
\end{array}$ & 1 \\
\hline $\begin{array}{l}\text { 2. Dificuldades ou entraves } \\
\text { burocráticos para se utilizar as } \\
\text { fontes de financiamento existentes }\end{array}$ & $\begin{array}{c}9 \\
20,5 \% \\
\end{array}$ & $\begin{array}{c}4 \\
9,1 \% \\
\end{array}$ & $\begin{array}{c}8 \\
18,2 \% \\
\end{array}$ & $\begin{array}{r}23 \\
52,3 \% \\
\end{array}$ & 0,66 & $\begin{array}{c}0 \\
0,0 \% \\
\end{array}$ & $\begin{array}{c}0 \\
0,0 \% \\
\end{array}$ & $\begin{array}{c}0 \\
0,0 \% \\
\end{array}$ & $\begin{array}{c}1 \\
100,0 \% \\
\end{array}$ & 1 & $\begin{array}{c}0 \\
0,0 \% \\
\end{array}$ & $\begin{array}{c}0 \\
0,0 \% \\
\end{array}$ & $\begin{array}{c}0 \\
0,0 \% \\
\end{array}$ & $\begin{array}{c}1 \\
100,0 \% \\
\end{array}$ & 1 \\
\hline $\begin{array}{l}\text { 3. Exigência de aval/garantias por } \\
\text { parte das instituiçōes de } \\
\text { financiamento }\end{array}$ & $\begin{array}{c}11 \\
25,0 \% \\
\end{array}$ & $\begin{array}{c}3 \\
6,8 \% \\
\end{array}$ & $\begin{array}{c}5 \\
11,4 \% \\
\end{array}$ & $\begin{array}{r}25 \\
56,8 \% \\
\end{array}$ & 0,66 & $\begin{array}{c}0 \\
0,0 \% \\
\end{array}$ & $\begin{array}{c}0 \\
0,0 \% \\
\end{array}$ & $\begin{array}{c}0 \\
0,0 \% \\
\end{array}$ & $\begin{array}{c}1 \\
100,0 \% \\
\end{array}$ & 1 & $\begin{array}{c}0 \\
0,0 \% \\
\end{array}$ & $\begin{array}{c}0 \\
0,0 \% \\
\end{array}$ & $\begin{array}{c}0 \\
0,0 \% \\
\end{array}$ & $\begin{array}{c}1 \\
100,0 \% \\
\end{array}$ & 1 \\
\hline $\begin{array}{l}\text { 4. Entraves fiscais que impedem o } \\
\text { acesso às fontes oficiais de } \\
\text { financiamento }\end{array}$ & $\begin{array}{r}25 \\
56,8 \% \\
\end{array}$ & $\begin{array}{c}2 \\
4,5 \% \\
\end{array}$ & $\begin{array}{c}7 \\
15,9 \% \\
\end{array}$ & $\begin{array}{c}10 \\
22,7 \% \\
\end{array}$ & 0,34 & $\begin{array}{c}1 \\
100,0 \% \\
\end{array}$ & $\begin{array}{c}0 \\
0,0 \% \\
\end{array}$ & $\begin{array}{c}0 \\
0,0 \% \\
\end{array}$ & $\begin{array}{c}0 \\
0,0 \% \\
\end{array}$ & 0 & $\begin{array}{c}0 \\
0,0 \% \\
\end{array}$ & $\begin{array}{c}0 \\
0,0 \% \\
\end{array}$ & $\begin{array}{c}0 \\
0,0 \% \\
\end{array}$ & $\begin{array}{c}1 \\
100,0 \% \\
\end{array}$ & 1 \\
\hline 5. Outras & $\begin{array}{c}40 \\
93,0 \%\end{array}$ & $\begin{array}{c}0 \\
0,0 \%\end{array}$ & $\begin{array}{c}0 \\
0,0 \%\end{array}$ & $\begin{array}{c}3 \\
7,0 \%\end{array}$ & 0,07 & $\begin{array}{c}1 \\
100,0 \%\end{array}$ & $\begin{array}{c}0 \\
0,0 \%\end{array}$ & $\begin{array}{c}0 \\
0,0 \%\end{array}$ & $\begin{array}{c}0 \\
0,0 \%\end{array}$ & 0 & $\begin{array}{c}0 \\
0,0 \%\end{array}$ & $\begin{array}{c}0 \\
0,0 \%\end{array}$ & $\begin{array}{c}0 \\
0,0 \%\end{array}$ & $\begin{array}{c}0 \\
0,0 \%\end{array}$ & 0 \\
\hline
\end{tabular}

Fonte: pesquisa de campo.

*Índice $=\left(0^{*} \mathrm{~N}^{\mathrm{O}}\right.$ nulas $+0,3 * \mathrm{~N}^{\mathrm{O}}$ baixas $+0,6{ }^{*} \mathrm{~N}^{\mathrm{O}}$ médias $+\mathrm{N}^{\mathrm{O}}$ altas $) /\left(\mathrm{N}^{\mathrm{O}}\right.$ empresas no segmento $)$. 


\section{CONSIDERAÇÕES FINAIS}

O artesanato na Região Metropolitana de Belém apresenta algumas características que podem ser consideradas comuns a esse tipo de atividades e outras, nem tanto. A característica comum é o caráter familiar da atividade, observado nas relações de trabalho - não havendo, em alguns casos, relações de assalariamento explícitas -, na transmissão do conhecimento (ofício) e nas formas de organização da produção. As características específicas estão relacionadas à diferenciação do produto local. Constata-se uma diversificação muito grande na utilização de matéria-prima de origem natural, bem como na produção de peças que retratam a vida cotidiana e a cultura da população local.

Existem várias características que identificam o conjunto das atividades artesanais como um arranjo produtivo local informal. São elas: a elevada informalidade, a forte tradição familiar que marca todos os elementos estruturais da empresa, como as relações de trabalho, a forma de apreensão e de transmissão de conhecimento, com reflexos na dinâmica de inovação do produto. Outras características observadas foram o crescente grau de cooperação e de associativismo, especialmente induzido ou coordenado pelo Estado.

Embora o artesão tenha consciência de que seu principal diferencial competitivo é a originalidade, a utilização de matéria-prima natural, que imprime a marca "Amazônia" a seus produtos, sabe que isso não é suficiente para competir tanto no mercado nacional, como no mercado externo. É preciso aliar a qualidade da matéria-prima e a qualidade do produto a uma escala maior de produção, para garantir uma redução nos custos e, dessa forma, colocar seus produtos a preços mais competitivos no mercado.

Para os artesãos, as principais dificuldades da atividade são a gestão dos custos - tanto os fixos, relacionados a investimentos, como os afetos ao capital de giro - e a falta de acesso ao crédito, em grande parte em razão do caráter informal da atividade.

Por fim, os artesãos ressaltam que, para alavancar o setor, especialmente naqueles segmentos com maior visibilidade internacional, são necessárias políticas públicas afirmativas, que permitam o aumento da capacitação da mão-de-obra, a melhoria da educação básica e o acesso a linhas de crédito e a outras formas de financiamento. 


\section{REFERÊNCIAS}

CACCIAMALI, Maria Cristina. Setor informal urbano e formas de participação na produção. São Paulo: IPE/USP, 1983 (Série Ensaios Econômicos, n. 26).

CACCIAMALI, Maria Cristina. Globalização e processo de informalidade. São Paulo: IPE/USP, 2000. Texto para discussão, n. 1.

CASSIOLATO, J. E.; LASTRES, H. M. M. O foco em arranjos produtivos e inovativos locais de micro e pequenas empresas. In: LASTRES, H. M. M.; CASSIOLATO, J. E.; MACIEL, M. L. Pequena empresa: cooperação e desenvolvimento local. Rio de Janeiro: Relume Dumará, p. 21-65, 2003a.

CASSIOLATO, J. E.; LASTRES, H. M. M. Uma caracterização de arranjos produtivos locais de micro e pequenas empresas. In: LASTRES, H. M. M.; CASSIOLATO, J. E.; MACIEL, M. L. Pequena empresa: cooperação e desenvolvimento local. Rio de Janeiro: Relume Dumará, cap. 2, 2003b.

INSTITUTO BRASILEIRO DE GEOGRAFIA E ESTATÍSTICA. Economia informal urbana. Rio de Janeiro, 2005.

KON, Anita. Economia dos serviços: teoria e evolução no Brasil. Rio de Janeiro: Elsevier, 2004.

LASTRES, Helena M. M.; CASSIOLATO, José E; ARROIO, Ana. Sistema de inovação e desenvolvimento: mitos e realidade da economia do conhecimento global. In: LASTRES, Helena M. M.; CASSIOLATO, José E.; ARROIO, Ana (Org.). Conhecimento, sistemas de inovação e desenvolvimento. Rio de Janeiro: Editora UFRJ, 2005.

MENDES, Armando Dias. Amazônia: modos de (o)usar. Manaus: Valer, 2001.

NORONHA, E. C.; TURCHI, L. Política Industrial e Ambiente Institucional na Análise de Arranjo Produtivos Locais. Brasília. IPEA, 2005.

ORGANIZAÇÃO INTERNACIONAL DO TRABALHO - OIT. Employment, Income, and Iquality: A Strategy for Increasing Employment in Kenya, Geneve: OIT. 1972. 
PAMPLONA, João Batista. A reemergência do auto-emprego urbano e suas implicações para o mercado de trabalho. In: ENCONTRO NACIONAL DE ECONOMIA POLÍTICA, 4., 1999, Porto Alegre. Anais... Porto Alegre, v. 1, 1999.

SANTOS, Fabiana; CROCCO, Marco; LEMOS, Mauro Borges. Arranjos e sistemas produtivos locais em "espaços industriais" periféricos: estudo comparativo de dois casos brasileiros. Belo Horizonte: UFMG, CEDEPLAR, 2002. Texto para discussão, n. 182.

SERVIÇO DE APOIO ÀS MICROS E PEQUENAS EMPRESAS DO PARÁ; INSTITUTO ACERTAR. Mapeamento do artesanato no Estado do Pará. Belém, 2002. 